\title{
Measured resolved shear stresses and Bishop-Hill stress states in individual grains of austenitic stainless steel
}

Juul, Nicolai Ytterdal; Oddershede, Jette; Beaudoin, Armand ; Chatterjee, Kamalika ; K.A. Koker, Margaret; Dale, Darren; Shade, Paul; Winther, Grethe

Published in:

Acta Materialia

Link to article, DOI:

10.1016/j.actamat.2017.09.021

Publication date:

2017

Document Version

Peer reviewed version

Link back to DTU Orbit

Citation $(A P A)$ :

Juul, N. Y., Oddershede, J., Beaudoin, A., Chatterjee, K., K.A. Koker, M., Dale, D., Shade, P., \& Winther, G. (2017). Measured resolved shear stresses and Bishop-Hill stress states in individual grains of austenitic stainless steel. Acta Materialia, 141, 388-404. https://doi.org/10.1016/j.actamat.2017.09.021

\section{General rights}

Copyright and moral rights for the publications made accessible in the public portal are retained by the authors and/or other copyright owners and it is a condition of accessing publications that users recognise and abide by the legal requirements associated with these rights.

- Users may download and print one copy of any publication from the public portal for the purpose of private study or research.

- You may not further distribute the material or use it for any profit-making activity or commercial gain

- You may freely distribute the URL identifying the publication in the public portal 


\section{Accepted Manuscript}

Measured resolved shear stresses and Bishop-Hill stress states in individual grains of austenitic stainless steel

Nicolai Ytterdal Juul, Jette Oddershede, Armand Beaudoin, Kamalika Chatterjee,

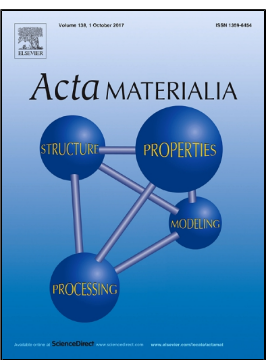
Margaret K.A. Koker, Darren Dale, Paul Shade, Grethe Winther

PII: S1359-6454(17)30757-7

DOI: 10.1016/j.actamat.2017.09.021

Reference: AM 14051

To appear in: Acta Materialia

Received Date: 06 July 2017

Revised Date: 29 August 2017

Accepted Date: 12 September 2017

Please cite this article as: Nicolai Ytterdal Juul, Jette Oddershede, Armand Beaudoin, Kamalika Chatterjee, Margaret K.A. Koker, Darren Dale, Paul Shade, Grethe Winther, Measured resolved shear stresses and Bishop-Hill stress states in individual grains of austenitic stainless steel, Acta Materialia (2017), doi: 10.1016/j.actamat.2017.09.021

This is a PDF file of an unedited manuscript that has been accepted for publication. As a service to our customers we are providing this early version of the manuscript. The manuscript will undergo copyediting, typesetting, and review of the resulting proof before it is published in its final form. Please note that during the production process errors may be discovered which could affect the content, and all legal disclaimers that apply to the journal pertain. 


\title{
Measured resolved shear stresses and Bishop-Hill stress states in individual grains of austenitic stainless steel
}

Nicolai Ytterdal Juula, Jette Oddershede ${ }^{b, c}$, Armand Beaudoin ${ }^{\text {d,e }}$, Kamalika Chatterjee ${ }^{\text {, }}$, Margaret K.A. Koker ${ }^{\mathrm{e}}$, Darren Dale ${ }^{\mathrm{e}}$, Paul Shade ${ }^{\mathrm{f}}$ and Grethe Winther ${ }^{\mathrm{a},{ }^{*}}$

aDepartment of Mechanical Engineering, Technical University of Denmark, Produktionstorvet 425, 2800 Kgs. Lyngby, Denmark

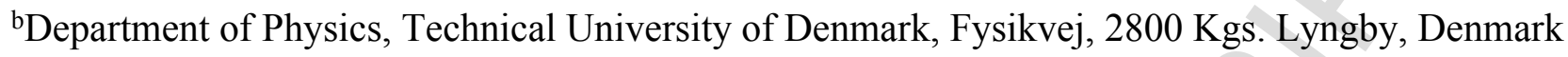

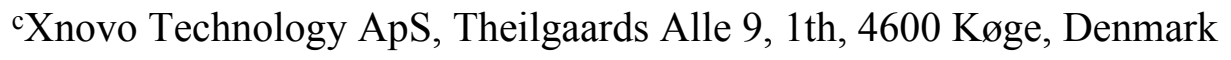

dDepartment of Mechanical Science and Engineering, University of Illinois at Urbana-Champaign, Champaign, IL, USA

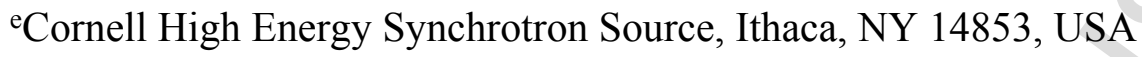

${ }_{\mathrm{f}}$ Materials and Manufacturing Directorate, Air Force Research Laboratory, Wright-Patterson AFB, OH 45433, USA

\begin{abstract}
The full three-dimensional stress state of 172 individual bulk grains in austenitic stainless steel $316 \mathrm{~L}$ at 0.1 and $1 \%$ sample elongation has been determined with sufficient accuracy to allow comparison with the theoretical Bishop-Hill stress states for plastically deforming grains as well as calculation of the resolved shear stresses on the individual slip systems. At $0.1 \%$, the resolved shear stresses exhibit quite large variations between grains of similar orientation. When averaging over similarly oriented grains, the resolved shear stresses correspond to the Schmid factors for uniaxial tension. At $1 \%$, only about half of the grains were close to a Bishop-Hill stress state. The stress state of the other half of the grains was closer to the applied uniaxial stress, in between Bishop-Hill states, or in some cases none of these. The orientation dependence of the assigned stress states deviate somewhat from the theoretical expectation. These deviations are found to originate from a larger tensile stress component than in the theoretical Bishop-Hill stress states and to be associated also with deviations from axisymmetric plastic strain. This conclusion was supported by finite-element crystal plasticity simulations.
\end{abstract}

\section{Keywords}

Austenitic stainless steels, Stress and strain, Resolved shear stresses, Synchrotron diffraction, Polycrystal plasticity modelling 


\section{Introduction}

The evolution of deformation textures in metals has a large impact on the properties of the metal, in particular mechanical anisotropy [1-3]. Thus, texture optimization is an important industrial field, and even small texture variations between batches may have large consequences. The ability to predict the texture evolution and the associated properties has therefore been the goal of much research. For this purpose, polycrystal plasticity models of increasing complexity have been proposed and evaluated. These models differ in the basic assumptions about grain interactions. Increasingly complex and detailed interactions have been included in the modelling. The classical Taylor/BishopHill model [4,5] from the first half of the twentieth century assumed that all grains deform with the same strain. Later, relaxed constraints models [6,7] have been developed to allow for fluctuations in certain strain components, physically motivated by elongated grain shapes. Also self-consistent models [8,9], which take the interaction between all grains of a certain orientation and a matrix representing the average behaviour of all other grains in the sample into account, have been derived. It is common to these models that their input and output are in the form of discretised bulk textures, which only give the volume fraction of material with specific crystallographic orientations. Although many of these models are quite successful at the level of bulk textures, they do not take the real threedimensional grain structure into account.

With the advent of finite-element-based [10-12] and Fourier-transformation-based [13] crystal plasticity, interactions between large ensembles of grains with different orientations, sizes and shapes can be modelled in more detail. While texture predictions may still be refined, the influence of local heterogeneities in the deforming grain structure on the nucleation and propagation of damage and eventually fracture also receives attention [14-16]. For the aforementioned purposes, studies of individual grains are necessary, and therefore more information on the three-dimensional grain structure is desired.

By means of synchrotron radiation and three-dimensional X-ray diffraction (3DXRD) microscopy [17], three-dimensional maps of the grain structure can be obtained. Each grain in such a map may be characterized with respect to e.g. crystallographic orientation, size and position as well as mean elastic strain tensor. As the technique is non-destructive, the evolution of these parameters during e.g. a tensile test may be monitored [15,18-23]. Comparison of the experimental grain structure evolution with model predictions is important both for validating the models and as inspiration for model improvement.

A fundamental issue in every crystal plasticity model is the prediction of the active slip systems in each grain, i.e. the crystallographic planes and directions in which dislocation glide leads to a permanent shape change of the crystal. The 3DXRD technique is not yet capable of monitoring gliding dislocations in each grain of a polycrystal, although progress in this direction is rapid [24]. The lattice rotation associated with the plastic deformation may, however, be monitored and employed to deduce the active slip systems. This is an indirect method, and unfortunately, the lattice rotations do not map uniquely to the active slip systems for a number of reasons. A major obstacle is that the local plastic strain tensor is not determined by the diffraction (but may be monitored in parallel by tomographic techniques [25]). The fact that not even the number of active slip systems can be taken as a known quantity further complicates the analysis.

According to the classical models by Taylor and Bishop-Hill, five linearly independent slip systems are in general needed to obtain an arbitrary strain. Activation of a slip system requires that it is critically stressed, i.e. that the shear stress resolved on the slip system exceeds a threshold value. In 
face-centred-cubic metals, there will always be either six or eight slip systems that are critically stressed under the arbitrary strain requirement. A total of 28 so-called Bishop-Hill stress states with six or eight critically stressed systems exist, but due to symmetry this number may be restricted to five. In uniaxial tension, grains with all five stress states are expected, depending on the crystallographic direction of the tensile axis. By contrast to the Taylor/Bishop-Hill model, relaxed constraint models, self-consistent models and finite-element-based crystal plasticity models often predict fewer than five active slip systems in a grain because these models do not assume that all grains deform with the same plastic strain increment.

A direct way of investigating which slip systems may be active in each grain is to investigate the stress state of the grain. From experimentally measured elastic strain tensors of individual grains by 3DXRD, the mean stress state (Type II stress [26]) may be calculated by means of the single crystal elastic constants. Subsequent calculation of the resolved shear stresses (RSS) on individual slip systems is then possible.

The aim of the present paper is to employ 3DXRD microscopy to determine the resolved shear stresses - and thus the potentially active slip systems - in a face-centred cubic metal under tensile loading at $0.1 \%$ deformation (presumably in the elasto-plastic regime) and $1 \%$ deformation (well into the plastic regime). While all grains in the sample are analysed, special focus is on grains of five specific orientations. These are selected to compare the experimental data with the five theoretical Bishop-Hill stress states. Finally the experimentally determined stress states are compared to predictions by finite-element-based crystal plasticity modelling with the experimentally investigated grain structure as input.

The material selected for this study of RSS in face-centred cubic metals is an austenitic stainless steel. This material is preferred over other classical representatives of the face-centred cubic metals, like copper and aluminium, because of the significantly larger elastic strains, defined by the ratio between the yield stress and elastic modulus. The elastic strains are therefore easier to measure accurately, meaning also an improved accuracy of the determined RSS-values. In addition, from an application point of view austenitic stainless steels are widely used because of their high formability, mechanical strength and good corrosion resistance.

\section{Experimental}

The sample material is a fully recrystallized austenitic 316 L stainless-steel, with an average grain diameter of $70 \mu \mathrm{m}$. A tensile sample with a cross-section of $0.7 \times 0.7 \mathrm{~mm}^{2}$ and a gauge length of 8 $\mathrm{mm}$ was produced by electric discharge machining.

The 3DXRD experiment was conducted at Cornell High Energy Synchrotron Source (CHESS) at beamline F2. A schematic of the setup is included in Figure 1b. The detector was a GE Revolution 41RT [27], with a pixel size of $200 \mu \mathrm{m} \times 200 \mu \mathrm{m}$ distanced $700 \mathrm{~mm}$ from the sample. The sample was illuminated with a box beam defined by a $0.10 \mathrm{~mm}$ vertical by $2.0 \mathrm{~mm}$ horizontal slit. The energy of the beam was $56.618 \mathrm{keV}$. The load frame RAMS2 (Rotation and Axial Motion System, $2^{\text {nd }}$ build) [28] was used to load the sample in uniaxial tension while simultaneously allowing illumination of the sample over a rotation range of $360^{\circ}$ in $\omega$ with a sampling interval of $0.25^{\circ}$. In total five layers along the vertical 3 -direction were scanned. The exposure time was $0.5 \mathrm{~s}$ per image, leading to a total scan time of 12 minutes per $0.10 \mathrm{~mm}$ section. 
The loading history of the sample was recorded using a digital image correlation (DIC) system [29] and a load cell. The stress-strain curve in Figure 1 presents the maximum stress reading after each loading step. Relaxation of the mechanical system was observed, but steady state was reached within a few minutes, i.e. before any 3DXRD data were recorded. At $1 \%$ deformation, the maximum tensile stress was $237 \mathrm{MPa}$, which after a few minutes had dropped to $199 \mathrm{MPa}$. After several hours the value was $197 \mathrm{MPa}$. The diffraction data was obtained for several load steps up to $5 \%$. At $0.1 \%$ deformation the 3DXRD measured volume weighted elastic strain along the tensile axis is $0.097 \pm 0.003 \%$. This indicates that elastic deformation prevails in most grains. At $1 \%$ deformation, the elastic tensile strain is about $10 \%$ of the total tensile strain.

\section{3DXRD data analysis}

For the reconstruction of the diffraction data, the FABLE software package was used [30]. The initial indexing of the diffraction spots to individual grains was conducted with GrainSpotter [31] for the undeformed state of the sample. The centre of mass (CMS) positions, orientations, relative volumes and elastic strains of individual grains at all load steps were fitted using FitAllB [32].

The reconstruction and fitting of the data is performed one layer at a time. In order to have a coherent map corresponding to the illuminated volume, the reconstructed layers must be merged into one map. This is done by comparing centre of mass and orientation of each grain segment in the neighbouring layers. Segments were merged into 3D grains if the distance between CMS was smaller than $100 \mu \mathrm{m}$ for $0 \%-0.1 \%$ deformation and $120 \mu \mathrm{m}$ for $1 \%$, and at the same time the misorientation should be smaller than $0.2^{\circ}$ and $0.7^{\circ}$, respectively. The strain and stress components of the merged grains are then obtained as the volume weighted average strain and stress components for each part of the grain. Details on the number of grains and indexed spots are listed in Table 1.

For each grain, the type II stress tensor was calculated based on the fitted elastic strains using the elastic constants: $c_{11}=206 \mathrm{MPa}, c_{12}=133 \mathrm{MPa}$, and $c_{44}=119 \mathrm{MPa}$ [33]. Error bars and covariance matrices on these parameters are estimated by the FitAllB program, see Table 1 . The volumeweighted stress along the tensile axis is $174 \mathrm{MPa}$ at $0.1 \%$ elongation and $205 \mathrm{MPa}$ at $1 \%$. These numbers agree well with the corresponding stress data from the load cell of 167 and $197 \mathrm{MPa}$, respectively, after relaxation. The mean error bars on the determined stress components are smaller than $10 \%$ of the stress along the tensile axis for deformation up to $1 \%$. At $3 \%$ deformation the error bars increase substantially due to smearing of the diffraction spots caused by intragranular orientation spread.

The resolved shear stresses for the twelve slip systems of the $\{111\}<110>$ family listed in BishopHill notation in Table 2 were determined from the full stress tensor for each grain. Error bars on all resolved shear stress components have been derived based on the covariance matrices from FitAllB and the relevant coordinate transformations. The mean error bars of the RSS at $0.1 \%$ and $1 \%$ deformation are 16 and $20 \mathrm{MPa}$, respectively. In order to compare the set of critically stressed slip systems in all the grains, the same variant of the 24 symmetrically equivalent crystallographic orientations was selected for all grains, namely the one with the tensile axis lying in the stereographic triangle spanned by [100]-[110]-[111]. In this triangle, slip system -b2 is expected to be the primary system.

Surface grains were excluded from the analysis to avoid relaxation effects at the free surface or residual stresses induced by the sample preparation. These grains were identified from the previously published 3D grain map constructed based on the near-field data [34]. A grain was classified as a 
surface grain if $20 \%$ or more of its volume was within $10 \mu \mathrm{m}$ of the free sample surface. In addition, all grains touching more than one sample surface were excluded, irrespective of their volume. It was verified by comparison with the other grains that the grains with less than $20 \%$ of the volume close to the surface did not exhibit extreme stress states. This is attributed to the measurement of the mean stress state of the grain (type II). After exclusion of 116 surface grains and further exclusion of 69 grains with relative error bars larger than 50\%, 172 grains are included in the analysis.

\section{$4 \quad$ RESULTS}

\subsection{General characterisation of stress states}

Figure 2 shows the grain-resolved elastic strain and stress along the tensile axis (3-axis) at both 0.1 and $1 \%$ deformation. It is seen that both strain and stress show substantial variations between grains. In general, however, the strain is highest and the stress lowest near [100]. Both the elastic strain and stress values increase with the sample elongation as expected. The stress/strain partitioning between grains from $0.1 \%$ deformation to $1 \%$ is qualitatively the same. This is in agreement with the fact that [100] is the elastically most compliant orientation and also the plastically softest.

Figure 3 presents three different parameters that are often employed to characterize a stress state, i.e. the coaxiality $[15,35]$, the triaxiality $[14,15]$ and the Lode angle [36]. The coaxiality is the angle between the uniaxial tensile stress applied to the entire sample and the measured stress, which is calculated for each grain from the elastic strain. Both are represented as the six-dimensional stress vectors $\left[\begin{array}{llllll}\sigma_{11} & \sigma_{22} & \sigma_{33} & \sigma_{12} & \sigma_{13} & \sigma_{23}\end{array}\right]$ :

$$
\text { coaxiality }=\operatorname{acos}\left(\frac{\sigma_{\text {applied }} \cdot \sigma_{\text {measured }}}{\left|\sigma_{\text {applied }}\right|\left|\sigma_{\text {measured }}\right|}\right)
$$

Equation 1

The triaxiality and the Lode angle are defined based on invariants to the stress tensor, $\sigma$, and the deviatoric stress tensor, $\sigma$ ':

$$
\begin{gathered}
I_{1}=\operatorname{tr}(\sigma) \\
J_{2}=\frac{1}{6}\left[\left(\sigma_{11}^{\prime}-\sigma_{22}^{\prime}\right)^{2}+\left(\sigma_{11}^{\prime}-\sigma_{33}^{\prime}\right)^{2}+\left({\sigma^{\prime}}_{22}-\sigma_{33}^{\prime}\right)^{2}\right]+\left({\sigma_{12}^{\prime}}^{2}+{\sigma_{13}^{\prime}}^{2}+\sigma_{23}^{\prime}{ }^{2}\right) \\
J_{3}=\operatorname{det}\left(\sigma^{\prime}\right)
\end{gathered}
$$

Equation 2

The triaxiality is defined as the ratio between the hydrostatic pressure and the von Mises stress, i.e.

$$
\text { triaxiality }=\frac{I_{1}}{3 \sqrt{3 J_{2}}} .
$$

Equation 3

The Lode angle is a measure of the magnitude of the intermediate principal stress component compared to the major and minor components. It may be defined in different ways and the following form is employed here: 


$$
\text { Lode } \left.=\operatorname{asin}\left(\frac{J_{3}}{2}\left(\frac{3}{J_{2}}\right)\right)^{1.5}\right) / 3
$$

For uniaxial stress, the coaxialty is 0 , the triaxiality $1 / 3$ and the Lode angle $\pi / 6 \approx 0.52$.

At $0.1 \%$ elongation, the macroscopically applied uniaxial and measured grain-resolved stresses are in general not coaxial, as evidenced by the mean coaxiality value of $18^{\circ}$. Furthermore, no particular orientation dependence is observed in Figure 3a). At $1 \%$ the mean coaxiality has decreased to $16^{\circ}$ and an orientation dependence can now be discerned in Figure 3b). The coaxiality angle has decreased substantially near [100], increased near [110] and in the middle of the triangle, whereas it has the same relatively low value near [111] as for $0.1 \%$.

At $0.1 \%$ elongation, the triaxiality is high near [100] and low near [110], see Figure 3c). About half of the grains are within 1.5 error bar from the value of $1 / 3$ for uniaxial tension. These grains are spread out over the entire triangle. When looking at the Figure 3d) for $1 \%$ elongation, the general picture is the same, except that the triaxiality near [100] in general approaches $1 / 3$, whereas the tendency for triaxialities significantly lower than $1 / 3$ has increased a little near [110].

The Lode angle has the highest values near the [100]-[111] line at $0.1 \%$ elongation and the lowest close to [110], see Figure 3e). The orientation dependence becomes even more pronounced at $1 \%$. As seen in Figure 3f) values close to 0.52 indicating a uniaxial principal stress state are found near [100] and [111], whereas lower values are observed at the middle of the [100]-[111] line. The lowest values approaching 0 are observed near [110]. This value corresponds to a plane stress or shear condition.

In summary, the investigated parameters indicate a fairly uniaxial stress state in many grains near [100] and [111]. By contrast, grains near [110] exhibit higher coaxiality angles, lower triaxiality and also lower Lode parameters, all of which reveal pronounced deviations from the macroscale uniaxial stress state.

\subsection{Detailed analysis of selected grain orientations}

In order to investigate the stress states in more detail, grains within $10^{\circ}$ of [100], [110] and [111] and $5^{\circ}$ of [321] and [ $\left.\begin{array}{lll}19 & 5 & 1\end{array}\right]$ were selected for closer analysis. The positions and expected Bishop-Hill stress states of the five orientations are illustrated in Figure 4. Their Schmid factors in uniaxial tension are listed in Table 3. Table 4 lists the critically stressed slip systems in the Bishop-Hill stress states. For the [110], [111] and [100] orientations, 4, 6 and 8 slip systems have the same Schmid factor, respectively. For [111] and [100] these also coincide with the systems of the expected Bishop-Hill stress states. The [321] orientation has the largest ratio between the Schmid factors of the most stressed primary system and the second most stressed one. In addition, [321] is close to the theoretical borderlines between three Bishop-Hill states. Finally, [ $\left.\begin{array}{llll}19 & 5 & 1\end{array}\right]$ is investigated as representative for the last Bishop-Hill stress state.

In the following, the measured RSS, including error bars, for all slip systems in a grain are presented in a histogram. In order to present the data in a condensed, yet representative manner, histograms for three grains are shown for each orientation. These three grains are selected to illustrate the variations among the grains in each orientation range. In addition, a histogram presenting the RSS for each slip system averaged over all grains in the selected orientation range near the ideal orientation are included. RSS-values for both 0.1 and 1\% strain are presented. The Bishop-Hill systems are marked 
in colour in the histograms. A lower bound on the critical RSS at yield is determined to be $72 \mathrm{MPa}$ as the ratio between $\sigma_{0.2}$ in the stress-strain curve in Figure 1 and the Taylor factor of 2.97 calculated by the standard Taylor/Bishop-Hill model. In order to accurately simulate the stress-strain curve in the finite-element crystal plasticity software Warp3D (see Figure 1 and section 5.3), a critical RSS at yield of $85 \mathrm{MPa}$ was employed. This corresponds to a ratio between $\sigma_{0.2}$ and the critical RSS of 2.5. Using the same ratio to estimate the critical RSS from the macroscopic stress of $230 \mathrm{MPa}$ at $1 \%$ deformation gives $92 \mathrm{MPa}$. For reference, the estimated critical RSS is marked by a horizontal line in each histogram.

Figure 5 shows RSS for the selected 22 grains close to [100]. At $0.1 \%$ deformation, the variations between the grains are quite large. Grains $A$ and $B$ represent the majority of the grains by having high RSS-values on the eight slip systems proposed by both Schmid and Bishop-Hill. However, the RSSvalues are not the same for all systems. Grain $C$ has a different configuration with only a few highly stressed systems. The mean configuration for the 22 grains studied closely matches the corresponding mean Schmid factors. When plastically deformed at $1 \%$, the difference between the systems has levelled out in grains $A$ and $C$. These two grains come close to the expected Bishop-Hill stress state (-BH2) where the eight slip systems are almost equally highly stressed within the error bars, while the remaining systems have a negligible RSS. This is the general case as demonstrated by the mean values for all grains. Grain B represents the few grains with less than eight critically stressed systems.

Seven grains within $4-10^{\circ}$ of [111] were characterised. This deviation makes the distribution of Schmid factors much less symmetrical than for the ideal [111]. Interestingly, the mean measured RSS-values at $0.1 \%$ deformation, presented in Figure 6, closely match the mean distribution of Schmid factors. Yet, the three selected grains exhibit fairly large variations. In particular, grains $E$ and $F$ have higher shear stress values resolved on the $a$-family of slip systems (i.e. on the (111) slip plane), than on the $c$-systems. After 1\% deformation, the RSS for half of the grains are high for all six systems expected, as exemplified by grain $D$. Grains $E$ and $F$ only have five highly stressed systems. On average, however, all seven investigated grains have six highly stressed systems and six systems with vanishing RSS, in agreement with the expected Bishop-Hill stress state (BH28).

Figure 7 shows the RSS values for the 19 selected grains within $10^{\circ}$ of [110]. In this orientation, four systems have high Schmid factors, while the expected Bishop-Hill stress state (BH6) has eight critically stressed systems. At $0.1 \%$ deformation, grains $G$ and $I$ have resolved shear stresses corresponding to the Schmid factors, which is also the mean result for the 19 grains. In grain H, only two systems have high RSS-values, six intermediate values and four systems are practically unstressed. After $1 \%$ deformation, grain $H$ has reached the expected Bishop-Hill state with eight critically stressed systems. This stress state was found for a third of the grains. Grain $G$ is the only grain in which the resolved shear stresses still correspond to the Schmid factors with only four high values. Grain $I$ has resolved shear stresses that lie in between grains $G$ and $H$, i.e. a stress state in between the Schmid factors and the expected Bishop-Hill state. Grain I is representative for the majority of the grains, meaning that on average, the 19 grains have four critically stressed systems corresponding to the Schmid factors but substantial RSS-values also on the four other systems in the expected Bishop-Hill state.

Figure 8 shows the RSS-values for the 26 grains oriented within $5^{\circ}$ of [321]. The majority of these grains have orientations expected to have the same Bishop-Hill stress state as [110] oriented grains (BH6). However, grains expected to be in the two neighbouring stress states, $\mathrm{BH} 17$ and $\mathrm{BH} 28$, are also included. The three grains selected are all in the region expected to be in BH6. At $0.1 \%$ deformation, grain $\mathrm{J}$ has six highly stressed slip systems which correspond to the BH17 stress state. 
Grain $K$ has resolved shear stresses in close agreement with its Schmid factors. Grain $L$ shows no agreement with any Bishop-Hill stress state or the Schmid factors. The mean resolved shear stresses, however, agree with the Schmid factors, when considering the error bars. At 1\% deformation, grain $J$ remains in $\mathrm{BH} 17$, grain $K$ has changed to $\mathrm{BH} 28$ as expected for grains near [111], whereas grain $L$ changed into BH6, expected for grains near [110]. The closest stress state for 13 of the grains is BH17, which is expected near the [100]-[111] line. According to the present data, however, it extends much further into the triangle than expected and dominates near [321] as also evidenced by the average RSS-values. The expected BH6 state is only found for 3 grains, while the BH28 state is found in 3 grains. In addition, 4 grains lie between $\mathrm{BH} 17$ and $\mathrm{BH} 28$ or $\mathrm{BH} 17$ and $\mathrm{BH} 6$, whereas the stress states of 4 grains did not resemble any Bishop-Hill state.

In Figure 9 the RSS-values for the grains within $5^{\circ}$ of [19 51 1] are presented. None of the eight grains of this orientation are in a Bishop-Hill stress state, neither at $0.1 \%$ nor $1 \%$ deformation. At $0.1 \%$, most grains have high RSS-values on $-\mathrm{a} 2$ and $-\mathrm{b} 2$, as also evidenced by the average RSS-values. The RSS-values of the other systems exhibit fairly large variations between the grains. Systems -a2 and $-\mathrm{b} 2$ are also those with the highest Schmid factors $(>0.47)$, but five other systems have Schmid factors in the range 0.27-0.38 (see Table 3). Detailed inspection of the measured RSS-values at $1 \%$ deformation identifies only a single grain within $5^{\circ}$ of [19 5 1] as being close to the -BH12 state expected from the orientation (grain $M$ ). Four of the eight grains are closer to the Bishop-Hill stress state found near [100] (e.g. grain $N$ ) and the remaining three, as exemplified by grain $O$, do not resemble any of the Bishop-Hill stress states (not even when considering all of the 28 possible states). On average the RSS-values at $1 \%$ resemble the average Schmid factors.

\subsection{Bishop-Hill stress states}

The analysis of individual grans in the previous section was conducted by visual inspection of the histograms of the RSS. In the present section, a qualitative comparison with the theoretical BishopHill stress states is carried out, encompassing the entire ensemble of 172 grains. For a grain to be in one of the theoretical Bishop-Hill stress states, all critically stressed systems in the Bishop-Hill stress state, $\mathrm{RSS}_{\mathrm{BH}}$, must have identical high measured RSS-values and the RSS of the remaining systems, $\mathrm{RSS}_{\mathrm{R}}$, must be vanishing. When comparing the experimentally measured RSS-values to the theoretical Bishop-Hill stress states, the experimental uncertainty must be considered. As a practical quantitative criterion, a threshold based on the mean error bar of the measured RSS in the grain, designated $\mathrm{K} \cdot \operatorname{err}(\mathrm{K}$ is a constant), was employed to determine the Bishop-Hill stress state. A BishopHill stress state is assigned to the grain if the following holds:

$$
\begin{gathered}
\max \left\{R S S_{B H}\right\}-\min \left\{R S S_{B H}\right\}<K \cdot \text { err } \\
\min \left\{R S S_{B H}\right\}>\max \left\{R S S_{R}\right\} \\
\max \left\{R S S_{R}\right\}<K \cdot \text { err }
\end{gathered}
$$

Equation 5

Physically, an increase in $\mathrm{K}$ corresponds to allowing larger variations between the critically stressed slip systems as well as larger values of the inactive system. To make a meaningful comparison, the minimum value of $\mathrm{K}$ is set to 2 . Considering that the error bar on the resolved shear stress averaged over all systems in all grains is $20 \mathrm{MPa}$, compared to the expected critical resolved shear stress of 92 $\mathrm{MPa}$, a K-value of 3 is deemed the largest meaningful threshold. For $\mathrm{K}$ equal to 2, 51 of the 172 grains (i.e. 30\%) are in a Bishop-Hill stress state at 1\% deformation. For $\mathrm{K}$ equal to 3 , this number increases to 90 grains $(52 \%)$. As a validation of the method it was verified that no grain was assigned 
to two Bishop-Hill stress states for the same value of $\mathrm{K}$. In addition, the grains determined to be in a Bishop-Hill state for $\mathrm{K}=2$ are with very few exceptions found to be in the same state using $\mathrm{K}=3$.

The assignment of Bishop-Hill stress states for $\mathrm{K}=3$ and $1 \%$ deformation is displayed in Figure 10, where also the theoretical subdivision from Figure 4 is included. The grains identified as being in a Bishop-Hill stress state are marked with circles, colour coded according to the determined BishopHill stress state. Crosses mark grains not in a Bishop-Hill stress state. The Bishop-Hill stress states are in particular found near [100], [110], [111] and at the centre of the stereographic triangle (near [321]). It is noteworthy that only three grains are found to be in the $-\mathrm{BH} 12$ state.

By comparison with the theoretical orientation dependence in Figure 4 (corresponding to the background colour in Figure 10), it is seen that the experimental range of BH17 (grey colour) extends much further into the triangle than expected and covers a large part of the theoretical BH6 region. This represents a substantial change in the systems that may be candidates for slip activity. Not only is the number of critically stressed slip systems in BH6 reduced from 8 to 6 by removal of the systems $-\mathrm{c} 1$ and $\mathrm{c} 2$. In addition, systems a1 and $\mathrm{d} 2$ in BH6 are replaced with a3 and d3 in BH17.

The experimental extension of - $\mathrm{BH} 12$ (orange colour) in Figure 10 is somewhat hard to determine as the only three grains found in this stress state more or less span the theoretical orientation range. However, it seems clear that $-\mathrm{BH} 2$ (red colour) dominates in most of this region. The change in slip systems from $-\mathrm{BH} 12$ to $-\mathrm{BH} 2$ is that $-\mathrm{c} 1$ and $-\mathrm{d} 1$ are replaced by $-\mathrm{c} 2$ and $-\mathrm{d} 2$. In fact the $-\mathrm{BH} 2$ stress state closely resembles the distribution of high Schmid factors for uniaxial tension for the [19 5 1] orientation.

\section{Discussion}

\subsection{Accuracy of measurements}

To employ the classification of Bishop-Hill stress states described in Equation 5, it is required that the error bars on the experimentally determined resolved shear stresses can be derived, and that these are less than approximately $20 \mathrm{MPa}$, considering that $\tau_{C R S S}=85 \mathrm{MPa}$ at $0.1 \%$ deformation. In the applied refinement program, FitAllB, the error estimation is based on assuming equal and diagonal covariance matrices for all observations (reflections) assigned to a specific grain, which has proven to work well for both simulations and experimental data [32], while other refinement codes work by propagating the experimental errors on individual reflections [37]. As can be seen from Table 1 and Figure 5-Figure 9, the stress error bars for the current experimental data are in fact within the desired range up to $1 \%$ elongation, while at $3 \%$ elongation the mean error bars on the tensile stress are four times higher and thus too large for meaningful comparison with Bishop-Hill stress states.

Previous 3DXRD experiments on elastically deformed IF steel to a stress of $60 \mathrm{MPa}$ [32] and $1.4 \%$ plastically deformed copper [38] were performed with limited rotation ranges $\left(2 \times 120^{\circ}\right)$ because of the geometry of the load frame. This resulted in asymmetric error bars in the stress components normal to the tensile axis, twice and three times the error bars in the tensile direction, respectively. This effect is also shown for relative percent errors in fitted stretch tensors based on simulated data for rotation ranges of $60^{\circ}$ and $120^{\circ}$, while it is much less pronounced for a $180^{\circ}$ rotation range [39]. The $360^{\circ}$ illumination of the sample performed in the present experiment eliminates this asymmetry, and the two components normal to the tensile axis both have the value listed in Table 1 . In addition, the error bars of the normal stress components are only $50 \%$ larger than for the tensile stress, presumably because of the more than 200 reflections assigned to each grain. Despite the obvious 
advantages of the $360^{\circ}$ illumination allowed by the RAMS2 load frame [28] it should be mentioned that resolved shear stresses on individual twinning and slip systems in hexagonal close packed metals ( $\mathrm{Mg}$, $\mathrm{Ti}$ and $\mathrm{Zr}$ deformed to a maximum of $2.8 \%$ ) have successfully been measured using limitedrange 3DXRD in the past [40-44].

\subsection{Stress states of the grains}

At $0.1 \%$ deformation in the elastic regime the resolved shear stresses vary considerably from grain to grain, even for grains of similar orientation. However, when averaging over similarly oriented grains the resolved shear stresses are close to the theoretical Schmid factors for uniaxial tension.

At $1 \%$ deformation, the resolved shear stresses come closer to the Bishop-Hill states and the similarity between similarly oriented grains increases. However, a Bishop-Hill stress state can only be assigned to at most half of the grains. Nevertheless, the comparison between the theoretical and experimentally determined Bishop-Hill stress states unambiguously reveals that the predicted orientation dependence of the Bishop-Hill stress states is incorrect. Both $\mathrm{BH} 17$ and $-\mathrm{BH} 2$ extend much further into the triangle than predicted, whereas the regions with the $\mathrm{BH} 6$ and - $\mathrm{BH} 12$ stress states are much smaller.

The Bishop-Hill stress states correspond to the vertices of the single crystal yield surface. As the Lode angle describes the principal stress values, the Lode angle for a theoretical Bishop-Hill stress state becomes invariant to the crystallographic grain orientation and is therefore constant throughout a Bishop-Hill stress state. The two theoretical Bishop-Hill stress states near [100] and [111] (-BH2 and $\mathrm{BH} 28$ ) both have a Lode angle of 0.52 , corresponding to uniaxial tension. The Lode angle for BH17 at the middle of the [100]-[111] line is 0.2 and the two remaining Bishop-Hill stress states (BH6 and -BH12) near [110] and [19 5 1] have Lode angles of 0, corresponding to plane stress.

When comparing these theoretical values to the experimental Lode angles for $1 \%$ elongation (in Figure 3f), good agreement is found: The highest Lode angles close to 0.52 are observed near [100] and [111] and the lowest values approaching 0 occur near [110]. Intermediate values are found at the middle of the [100]-[111] line. It is also clear that the experimentally determined Lode angles in the upper left part of the theoretical BH6 state are higher than those in the lower right corner in the immediate vicinity of [110]. This agrees with the conclusion that $\mathrm{BH} 17$ extends into the theoretical region of BH6. The same conclusion applies to the left part of the theoretical - BH12 stress state, where the experimental stress state is close to $-\mathrm{BH} 2$.

The Lode angles are consistently found to be close to or higher than the theoretical value for the Bishop-Hill stress state. As a high Lode angle indicates a stress state with a strong uniaxial tensile component, it must be concluded that the effect of the applied uniaxial stress on individual grains is stronger than expected by the Bishop-Hill model. This is in fact also observed for the grains of near [110] orientation, which have very low Lode angles, approaching the value for plane stress. The mean resolved shear stresses for the 19 grains within $10^{\circ}$ of [110] have significantly higher resolved shear stresses on the four systems with the highest Schmid factors in Table 3 than on the four other critically stressed systems of the BH6 stress state.

In summary, the stress states at $1 \%$ deformation, i.e. in the plastic regime, exhibit an overall orientation dependence, which deviates somewhat from the orientation dependence of the theoretical Bishop-Hill states. Where the experimental stress state differs significantly from a Bishop-Hill state, the resolved shear stresses often correlate with the grain orientation by resembling the Schmid factors in uniaxial tension or by lying in between those of two neighbouring Bishop-Hill states. Examples of stress states that could not be categorized within this framework were, however, also observed. 
The general grain orientation dependence of the stress state, and therefore the potentially active slip systems, agrees well with the overall observation of orientation dependent lattice rotations in tensile deformed aluminium [45] and interstitial-free steel [46]. Also dislocation structures in deformed grains of aluminium, copper and nickel [47-51] and hot-deformed austenite grains [52,53] exhibit grain orientation dependence, even to small grain sizes [54]. The coupling between the grain orientation dependent dislocation structures and the slip systems has further been confirmed by analysis of the Burgers vectors of the dislocations in the dislocation boundaries [55-58]. A recent analysis of the differences in rotation and intragranular orientation spread for similarly oriented grains in an interstitial-free steel also concluded that, despite inter- and intragranular variations in the plastic strain, the dominant slip systems in the similarly oriented grains were the same $[46,59]$.

\subsection{Comparison to finite-element crystal plasticity simulations}

The three-dimensional arrangement of the grains investigated above was previously mapped out by 3DXRD using a near-field detector [34]. A grain map without voids was obtained by a 3D generalization of GrainSweeper [60] with a low completeness. The map may be inaccurate with respect to the presence of small annealing twins, which are difficult to detect. It has, however, previously been demonstrated that the Type II stresses in twinned grains do not correlate [34].

A regular grid of cubic voxels was constructed from the map [61]. The microstructure was thereafter meshed into $67 \times 69 \times 50$ cubic 8 -noded elements by Neper [62]. The side length of each element is $10 \mu \mathrm{m}$, which is 4 times coarser than the experimental grain structure from the near-field map.

Isotropic hardening was implemented through the Voce law:

$$
\begin{gathered}
\tau=\tau_{C R S S}+\tau_{w} \\
\text { and } \\
\dot{\tau}_{w}=\theta_{0}\left(1-\frac{\tau_{w}}{\tau_{v}}\right)^{m} \sum_{s} \dot{\gamma}_{S}
\end{gathered}
$$

Equation 6

Equation 7

where $s$ sums over the slip systems. The quantities $\tau_{C R S S}$ and $\tau_{w}$ are the initial critical resolved shear stress of each slip system and the stress contribution from work-hardening, respectively. The workhardening depends on the shear, $\gamma$, on the slip systems in each grain. The parameters $\tau_{v}, m$ and $\theta_{0}$ in Equation 7 were set to reproduce the experimental stress-strain curve in Figure 1 and are listed in Table 5. The elastic parameters in the modelling were set to match the single crystal elastic constants employed to calculate the stress tensor from the 3DXRD data.

A tensile experiment in displacement control was simulated to $1 \%$ deformation using the Warp3D finite-element crystal plasticity code [63], while enforcing planarity of the top and bottom of the meshed volume. To avoid rigid body motion, a corner node at the bottom was fixed in the (1,2)-plane perpendicular to the tensile 3-axis and the 1-coordinate of another corner node in the same plane was fixed. In the simulations, the initial stress state of the grains was ignored. No attempt was made to account for the interaction with grains lying above or below the reconstructed volume.

Figure 11 presents the simulation results in the form of the tensile elastic strain and the tensile stress. Figure 12 presents the corresponding coaxiality, triaxiality and Lode angle. The general orientation dependence and the values of the investigated parameters agree with the experimental data in Figure 2 and Figure 3 . In summary, the mean coaxiality is less than $20^{\circ}$, high triaxiality is observed near 
[100], and Lode angles near the [100]-[111] line are high. Although not shown, neither the experimental data nor the simulation results reveals any particular orientation dependence of the hydrostatic pressure or grain size.

In spite of the good overall agreement, one-to-one correspondence was not obtained. In particular larger than predicted variations between similarly oriented grains were observed experimentally. Similar effects were also observed in a recent simulation study [35] of a titanium alloy conducted in the elastic regime. The initial stress states were not grain orientation dependent. However, there is a tendency that the grains, which exhibit large strains and stresses in the undeformed state, are also the grains with the highest values at 0.1 and $1 \%$ elongation. The experimental uncertainties do not fully explain this and an effect of the initial residual stress on the subsequent behaviour, as concluded in [35], can definitely not be ruled out. Attempts to take the residual stress into account in the modelling are in progress along the lines of [64].

The present data agree with the titanium alloy experiment in [35] by having very high coaxiality angles (present mean of $93^{\circ}$ ) in the undeformed state, which decrease substantially as soon as elastic deformation is applied. The present data extends into the plastic regime, revealing that the coaxiality near [110] increases again. This agrees with the lower Lode angles for these orientations, showing that the stress state deviates substantially from the uniaxial tensile stress applied.

The present material is highly elastically anisotropic and the ratio between the calculated Young's modulus along the stiffest and most compliant directions is 3 . At $0.1 \%$ elongation, the elastic anisotropy is responsible for the grain orientation dependence of the strain and stress data. The elastically most compliant direction is [100] and this direction therefore exhibits the largest tensile elastic strains and the smallest stresses. The [111] direction is the elastically stiffest and consequently exhibits the smallest tensile elastic strains and largest stresses. This is the origin of the grain orientation dependence of the triaxiality. According to the simulations, only a few grains have yielded at $0.1 \%$. The grains near [100] are the last to yield, although they are also the plastically softest. This is in agreement with a systematic study of the elasto-plastic transition in materials with different elastic anisotropy [65].

The Bishop-Hill stress states of the simulated grains at $1 \%$ elongation were determined in the same way as for the experimental data, using three times the mean experimental error bar of $20 \mathrm{MPa}$ to define the threshold in Equation 5. The result is displayed in Figure 13. The fraction of grains assigned to a Bishop-Hill stress state is $87 \%$, i.e. substantially larger than the $50 \%$ for the experimental data. The predicted orientation dependence of the simulated Bishop-Hill stress states agrees well with the experimental data in Figure 10. This also includes extension of BH17 into the upper left part of the BH6 region and of $-\mathrm{BH} 2$ into $-\mathrm{BH} 12$.

The simulated slip system activity in the 21 grains near [321], where BH17 is observed instead of the theoretically expected BH6, were analysed in more detail. It should be noted that according to the simulations, all grains are predicted to have slip on at least 5 systems, but the number of dominant active systems per grain is 1-4. Considering only the average slip activity for simplicity, the active slip systems carry the following shear, $\gamma$, in units of $10^{-2}$ at $1 \%$ elongation:

$$
\gamma_{\overline{b 2}}=1 ; \gamma_{b 1}=0.4 ; \gamma_{\overline{a 2}}=\gamma_{\overline{d 1}}=0.3 ; \gamma_{d 3}=0.1 ; \gamma_{a 3}=0.03 ; \gamma_{c 2}=0.01
$$

This means that the four systems, which are common to BH6 and BH17, are the most active. System $\mathrm{d} 3$ is only critically stressed in BH17 and the activities of the two remaining systems, of which one 
belongs to $\mathrm{BH} 6$ and the other to $\mathrm{BH} 17$, are negligible. This agrees with the finding of $\mathrm{BH} 17$ in the majority of these grains. Interestingly, axisymmetric tensile plastic strain cannot be obtained for these grain orientations in $\mathrm{BH} 17$. However, plastic strains which deviate a little from axial symmetry are possible. Using a reference orientation with [321] as the tensile 3-axis and [2-30] as the 1-axis, contractions along the 1 - and 2 -axes of -0.4 and -0.6 times the tensile strain, respectively, are possible in BH17. This gives a Taylor factor of 2.91, which should be compared with the value 3.15 obtained for axisymmetric tension in BH6. For further comparison, the simulated mean slip in the reference orientation introduces fairly small shear strains and contractions of -0.3 and -0.7 along the 1 - and 2axes. The corresponding Taylor factor of 2.19 indicates a significant reduction in the plastic work. It should be noted that the experimentally observed grains near [321] investigated here have their 1and 2- axes randomly distributed around the tensile axis, i.e. the finding of smaller contraction along the 1-axis for the selected reference orientation does not indicate that the entire sample exhibits this contraction. In fact the simulations with Warp3D for the entire sample gives a larger contraction along the 1-axis than along the 2-axis.

Similar arguments hold for the extension of $-\mathrm{BH} 2$ into the left part of $-\mathrm{BH} 12$. The simulated average slip in units of $10^{-2}$ at $1 \%$ elongation for the 15 grains theoretically expected to be in $-\mathrm{BH} 12$ but found to be in $-\mathrm{BH} 2$ is:

$$
\gamma_{\overline{b 2}}=0.7 ; \gamma_{\overline{a 2}}=\gamma_{d 3}=0.4 ; \gamma_{a 3}=0.2 ; \gamma_{b 3}=0.07 ; \gamma_{c 3}=0.05 ; \gamma_{\overline{c 2}}=\gamma_{\overline{d 1}}=0.02 ; \gamma_{b 1}=0.01
$$

The six most active systems are critically stressed in both $-\mathrm{BH} 2$ and $-\mathrm{BH} 12$. Of the remaining systems with negligible shears, one belongs to $-\mathrm{BH} 2$, another to $-\mathrm{BH} 12$ and the third to none of these stress states. The plastic strain obtained for a reference orientation with the tensile 3-axis along [25 5 1] and the 1-axis along [5 -25 0] corresponds to contractions along the 1- and 2-axes of -0.42 and 0.58 times the tensile strain, respectively. The shear components are small in comparison. Axisymmetric plastic strain is not possible in - $\mathrm{BH} 2$. However, with contractions along the 1- and 2axes of -0.44 and -0.56 , tensile deformation in $-\mathrm{BH} 2$ is possible. This deviation from axisymmetric deformation reduces the Taylor factor from 2.40 to 2.31. Again, the Taylor factor corresponding to the mean simulated slip in the 15 grains is significantly lower (1.89).

\section{Conclusions}

The stress state and resolved shear stresses in tensile deformed austenitic stainless steel (316L) have been determined experimentally and compared to the expected Bishop-Hill stress states for uniaxial tension at $0.1 \%$ and $1 \%$ deformation.

- The experimental set-up with a stable stress rig allowing $360^{\circ}$ illumination of the sample enables sufficiently small error bars on the resolved shear stresses to allow meaningful interpretation of the data.

- At $0.1 \%$, the resolved shear stresses exhibit quite large variations between grains of similar orientation. When averaging over similarly oriented grains, the resolved shear stresses correspond to the Schmid factors for uniaxial tension.

- At $1 \%$, the closest Bishop-Hill stress state was quantitatively determined for about half of the grains. The stress state of the other half of the grains was qualitatively categorized as being closer to the applied uniaxial stress, in between Bishop-Hill states, or in some cases none of these. 
- The orientation dependence of assigned Bishop-Hill stress states resembles the theoretical expectation with two exceptions:

- BH17 (near the [100]-[111] line) extends further into the stereographic triangle where $\mathrm{BH} 6$ is expected.

- $\quad-\mathrm{BH} 2$ (near [100]) extends into - BH12. The latter state was only identified in a few grains.

- The two exceptions are attributed to a larger effect of the applied uniaxial tensile stress than predicted by the Bishop-Hill model.

- Finite-element crystal plasticity simulations qualitatively reproduce the experimental stress states, including the deviations from the theoretical orientation dependence of the Bishop-Hill stress states. The simulations show that these deviations are also associated with deviations from axisymmetric tensile plastic strain and lowering of the plastic work. Agreement at the level of individual grains was, however, not obtained.

\section{Acknowledgements}

NYJ, JO and GW acknowledge support from the Danish Independent Research Council - Technology and Productions Sciences grant n. DFF-13555-00220. The Danish Agency for Science, Technology and Innovation is acknowledged for covering their expenses in relation to the synchrotron experiment (through Danscatt). AB and KC received support through the Air Force Office of Scientific Research under Contract No. FA9550-14-1-0369. PS acknowledges support from the Materials \& Manufacturing Directorate of the U.S. Air Force Research Laboratory. This work is based upon research conducted at the Cornell High Energy Synchrotron Source (CHESS), which is supported by the NSF \& NIH/NIGMS via NSF award DMR-1332208. 


\section{References}

[1] S. Kweon, D.S. Raja, Comparison of anisotropy evolution in BCC and FCC metals using crystal plasticity and texture analysis, Eur. J. Mech. - A/Solids. 62 (2017) 22-38.

[2] G. Winther, Effect of grain orientation dependent microstructures on flow stress anisotropy modelling, Scr. Mater. 52 (2005) 995-1000.

[3] K. Zhang, B. Holmedal, O. Hopperstad, S. Dumoulin, J. Gawad, A. Van Bael, P. Van Houtte, Multi-level modelling of mechanical anisotropy of commercial pure aluminium plate: Crystal plasticity models, advanced yield functions and parameter identification, Int. J. Plast. 66 (2015) $3-30$.

[4] G.I. Taylor, Plastic strain in metals, J. Inst. Met. 62 (1938) 307-324.

[5] J. Bishop, R. Hill, A theory of the plastic distortion of a polycrystalline aggregate under combined stresses, Philos. Mag. 42 (1951) 414-427.

[6] U.F. Kocks, H. Chandra, Slip geometry in partially contrained deformation, Acta Metall. 30 (1982) 695-709.

[7] P. Van Houtte, A Comprehensive Mathematical Formulation of an Extended Taylor-BishopHill Model Featuring Relaxed Constraints, the Renouard-Wintenberger Theory and a Strain Rate Sensitivity Model, Textures Microstruct. 8 (1988) 313-350.

[8] A. Molinari, G.R. Canova, S. Ahzi, A self consistent approach of the large deformation polycrystal viscoplasticity, Acta Metall. 35 (1987) 2983-2994.

[9] R.A. Lebensohn, C.N. Tomé, A self-consistent viscoplastic model: prediction of rolling textures of anisotropic polycrystals, Mater. Sci. Eng. A. 175 (1994) 71-82.

[10] D.P. Mika, P.R. Dawson, Effects of grain interaction on deformation in polycrystals, Mater. Sci. Eng. A. 257 (1998) 62-76.

[11] A.J. Beaudoin, P.R. Dawson, K.K. Mathur, U.F. Kocks, A hybrid finite element formulation for polycrystal plastictiy with consideration of macrostructural and microstructural linking, Int. J. Plast. 11 (1995) 501-521.

[12] F. Roters, P. Eisenlohr, L. Hantcherli, D.D. Tjahjanto, T.R. Bieler, D. Raabe, Overview of constitutive laws, kinematics, homogenization and multiscale methods in crystal plasticity finite-element modeling: Theory, experiments, applications, Acta Mater. 58 (2010) 11521211.

[13] R.A. Lebensohn, N-site modeling of a 3D viscoplastic polycrystal using fast fourier transform, Acta Mater. 49 (2001) 2723-2737.

[14] A.J. Beaudoin, M. Obstalecki, W. Tayon, M. Hernquist, R. Mudrock, P. Kenesei, U. Lienert, In situ assessment of lattice strain in an Al - Li alloy, Acta Mater. 61 (2013) 3456-3464.

[15] K. Chatterjee, A. Venkataraman, T. Garbaciak, J. Rotella, M.D. Sangid, A. Beaudoin, Study 
of grain-level deformation and residual stresses in Ti-7Al under combined bending and tension using high energy x-ray diffraction ( HEXD ), Int. J. Solids Struct. 94-95 (2015) 1-23.

[16] R.A. Lebensohn, R. Pokharel, Interpretation of Microstructural Effects on Porosity Evolution Using a Combined Dilatational/Crystal Plasticity Computational Approach, J. Mech. 66 (2014) 437-443.

[17] H.F. Poulsen, S.F. Nielsen, E.M. Lauridsen, S. Schmidt, R.M. Suter, Three-dimensional maps of grain boundaries and the stress state of individual grains in polycrystals and powders, J. Appl. Crystallogr. 34 (2001) 751-756.

[18] M. Obstalecki, S.L. Wong, P.R. Dawson, M.P. Miller, Quantitative analysis of crystal scale deformation heterogeneity during cyclic plasticity using high-energy X-ray diffraction and finite-element simulation, Acta Mater. 75 (2014) 259-272.

[19] D.C. Pagan, M.P. Miller, Connecting heterogeneous single slip to diffraction peak evolution in high-energy monochromatic X-ray experiments, J. Appl. Crystallogr. 47 (2014) 887-898.

[20] R. Pokharel, J. Lind, S.F. Li, P. Kenesei, R.A. Lebensohn, R.M. Suter, A.D. Rollett, In situ Observation of Bulk 3D Grain Evolution During Plastic Deformation in Polycrystalline Cu, Int. J. Plast. 67 (2015) 217-234.

[21] J.C. Schuren, P.A. Shade, J. V. Bernier, S.F. Li, B. Blank, J. Lind, P. Kenesei, U. Lienert, R.M. Suter, T.J. Turner, D.M. Dimiduk, J. Almer, New opportunities for quantitative tracking of polycrystal responses in three dimensions, Curr. Opin. SOLID STATE Mater. Sci. 19 (2015) 235-244.

[22] P. Sedmák, J. Pilch, L. Heller, J. Wright, P. Sedlák, M. Frost, P. Sittner, Grain-resolved analysis of localized deformation in nickel-titanium wire under tensile load, Science (80-. ). 353 (2016) 559-562.

[23] D.C. Pagan, P.A. Shade, N.R. Barton, J.-S. Park, P. Kenesei, D.B. Menasche, J. V. Bernier, Modeling slip system strength evolution in Ti-7Al informed by in-situ grain stress measurements, Acta Mater. 128 (2017) 406-417.

[24] H. Simons, A.C. Jakobsen, S.R. Ahl, C. Detlefs, H.F. Poulsen, Multiscale 3D characterization with dark-field x-ray microscopy, MRS Bull. 41 (2016) 454-459.

[25] H. Toda, T. Kamiko, Y. Tanabe, M. Kobayashi, D.J. Leclere, K. Uesugi, A. Takeuchi, K. Hirayama, Diffraction-amalgamated grain boundary tracking for mapping 3D crystallographic orientation and strain fields during plastic deformation, Acta Mater. 107 (2016) 310-324.

[26] P.J. Withers, H.K.D.H. Bhadeshia, Residual stress part 1 - Measurement techniques, Mater. Sci. Technol. 17 (2001) 355-365.

[27] J.H. Lee, C.C. Aydiner, J.D. Almer, J.V. Bernier, K.W. Chapman, P.J. Chupas, D.R. Haeffner, K. Kump, P.L. Lee, U. Lienert, A. Miceli, G. Vera, Synchrotron applications of an amorphous silicon flat-panel detector., J. Synchrotron Radiat. 15 (2008) 477-88.

[28] P.A. Shade, B. Blank, J.C. Schuren, T.J. Turner, P. Kenesei, K. Goetze, R.M. Suter, J. V. 
Bernier, S.F. Li, J. Lind, U. Lienert, J. Almer, A rotational and axial motion system load frame insert for in situ high energy x-ray studies, Rev. Sci. Instrum. 86 (2015) 93902.

[29] M. Guizar-Sicairos, S.T. Thurman, J.R. Fienup, Efficient subpixel image registration algorithms, Opt. Lett. 33 (2008) 156-158.

[30] H.O. Sørensen, S. Schmidt, J.P. Wright, G.B.M. Vaughan, S. Techert, E.F. Garman, J. Oddershede, J. Davaasambu, K.S. Paithankar, C. Gundlach, H.F. Poulsen, Multigrain crystallography, Zeitschrift Fur Krist. 227 (2012) 63-78.

[31] S. Schmidt, GrainSpotter: a fast and robust polycrystalline indexing algorithm, J. Appl. Crystallogr. 47 (2014) 276-284.

[32] J. Oddershede, S. Schmidt, H.F. Poulsen, H.O. Sørensen, J. Wright, W. Reimers, Determining grain resolved stresses in polycrystalline materials using three-dimensional X-ray diffraction, J. Appl. Crystallogr. 43 (2010) 539-549.

[33] H.M. Ledbetter, Predicted single-crystal elastic constants of stainless-steel 316, Br. J. NonDestructive Test. 23 (1981) 286-287.

[34] N.Y. Juul, G. Winther, D. Dale, M.K.A. Koker, P. Shade, J. Oddershede, Elastic interaction between twins during tensile deformation of austenitic stainless steel, Scr. Mater. 120 (2016) $1-4$.

[35] T.J. Turner, P.A. Shade, J. V. Bernier, S.F. Li, J.C. Schuren, P. Kenesei, R.M. Suter, J. Almer, Crystal Plasticity Model Validation Using Combined High-Energy Diffraction Microscopy Data for a Ti-7Al Specimen, Metall. Mater. Trans. A. 48 (2017) 627-647.

[36] A.A. Benzerga, J.B. Leblond, Ductile Fracture by Void Growth to Coalescence, Adv. Appl. Mech. 44 (2010) 169-305.

[37] J.K. Edmiston, J. V. Bernier, N.R. Barton, G.C. Johnson, Lattice refinement strategies, Acta Crystallogr. Sect. A Found. Crystallogr. 68 (2012) 181-187.

[38] J. Oddershede, S. Schmidt, H.F. Poulsen, L. Margulies, J. Wright, M. Moscicki, W. Reimers, G. Winther, Grain-resolved elastic strains in deformed copper measured by three-dimensional X-ray diffraction, Mater. Charact. 62 (2011) 651-660.

[39] J. V. Bernier, N.R. Barton, U. Lienert, M.P. Miller, Far-field high-energy diffraction microscopy: a tool for intergranular orientation and strain analysis, J. Strain Anal. Eng. Des. 46 (2011) 527-547.

[40] C.C. Aydiner, J. V. Bernier, B. Clausen, U. Lienert, C.N. Tomé, D.W. Brown, Evolution of stress in individual grains and twins in a magnesium alloy aggregate, Phys. Rev. B - Condens. Matter Mater. Phys. 80 (2009) 1-6.

[41] T.R. Bieler, L. Wang, A.J. Beaudoin, P. Kenesei, U. Lienert, In Situ Characterization of Twin Nucleation in Pure Ti Using 3D-XRD, Metall. Mater. Trans. A. 45A (2014) 109-122.

[42] H. Abdolvand, M. Majkut, J. Oddershede, S. Schmidt, U. Lienert, B.J. Diak, P.J. Withers, M.R. 
Daymond, On the deformation twinning of Mg AZ31B: A three-dimensional synchrotron Xray diffraction experiment and crystal plasticity finite element model, Int. J. Plast. 70 (2015) 77-97.

[43] H. Abdolvand, M. Majkut, J. Oddershede, J.P. Wright, M.R. Daymond, Study of 3-D stress development in parent and twin pairs of a hexagonal close-packed polycrystal: Part I - in-situ three-dimensional synchrotron X-ray diffraction measurement, Acta Mater. 93 (2015) 246255.

[44] L. Wang, Z. Zheng, H. Phukan, P. Kenesei, J. Park, J. Lind, R.M. Suter, T.R. Bieler, Direct measurement of critical resolved shear stress of prismatic and basal slip in polycrystalline $\mathrm{Ti}$ using high energy X-ray diffraction microscopy, Acta Mater. 132 (2017) 598-610.

[45] G. Winther, L. Margulies, S. Schmidt, H.F. Poulsen, Lattice rotations of individual bulk grains Part II: correlation with initial orientation and model comparison, Acta Mater. 52 (2004) 28632872.

[46] J. Oddershede, J.P. Wright, A. Beaudoin, G. Winther, Deformation-induced orientation spread in individual bulk grains of an interstitial-free steel, Acta Mater. 85 (2015) 301-313.

[47] N. Hansen, X. Huang, W. Pantleon, G. Winther, Grain orientation and dislocation patterns, Philos. Mag. 86 (2006) 3981-3994.

[48] X. Huang, G. Winther, Dislocation structures. Part I. Grain orientation dependence, Philos. Mag. 87 (2007) 5189-5214.

[49] G. Winther, X. Huang, Dislocation structures. Part II. Slip system dependence, Philos. Mag. 87 (2007) 5215-5235.

[50] X. Huang, G. Winther, N. Hansen, T. Hebesberger, A. Vorhauer, R. Pippan, M. Zehetbauer, Microstructures of nickel deformed by high pressure torsion to high strains, in: Thermec 2003, Madrid, 2003: pp. 2819-2824.

[51] G.M. Le, A. Godfrey, C.S. Hong, X. Huang, G. Winther, Orientation dependence of the deformation microstructure in compressed aluminum, Scr. Mater. 66 (2012) 359-362.

[52] D. Poddar, P. Cizek, H. Beladi, P.D. Hodgson, Orientation Dependence of the Deformation Microstructure in a Fe-30Ni-Nb Model Austenitic Steel Subjected to Hot Uniaxial Compression, Metall. Mater. Trans. A. 46 (2015) 5933-5951.

[53] D. Poddar, P. Cizek, H. Beladi, P.D. Hodgson, Microstructure characteristics of the (111) oriented grains in a Fe-30Ni-Nb model austenitic steel deformed in hot uniaxial compression, Mater. Charact. 118 (2016) 382-396.

[54] G. Le, A. Godfrey, N. Hansen, W. Liu, G. Winther, X. Huang, Influence of grain size in the near-micrometre regime on the deformation microstructure in aluminium, Acta Mater. 61 (2013) 7072-7086.

[55] R.J. McCabe, A. Misra, T.E. Mitchell, Experimentally determined content of a geometrically necessary dislocation boundary in copper, Acta Mater. 52 (2004) 705-714. 
[56] Y. Wei, A. Godfrey, W. Liu, Q. Liu, X. Huang, N. Hansen, G. Winther, Dislocations, boundaries and slip systems in cube grains of rolled aluminium, Scr. Mater. 65 (2011) 355358.

[57] C.S. Hong, X. Huang, G. Winther, Dislocation content of geometrically necessary boundaries aligned with slip planes in rolled aluminium, Philos. Mag. 93 (2013) 3118-3141.

[58] G. Winther, C.S. Hong, X. Huang, Low-Energy Dislocation Structure (LEDS) character of dislocation boundaries aligned with slip planes in rolled aluminium, Philos. Mag. 95 (2015) 1471-1489.

[59] G. Winther, J.P. Wright, S. Schmidt, J. Oddershede, Grain interaction mechanism leading to intragranular orientation spread in tensile deformed bulk grains of interstitial-free steel, Int. J. Plast. 88 (2017) 108-125.

[60] S. Schmidt, U.L. Olsen, H.F. Poulsen, H.O. Sørensen, E.M. Lauridsen, L. Margulies, C. Maurice, D. Juul Jensen, Direct observation of 3-D grain growth in Al-0.1\% Mn, Scr. Mater. 59 (2008) 491-494.

[61] J.M. Dake, J. Oddershede, H.O. Sørensen, T. Werz, J.C. Shatto, K. Uesugi, S. Schmidt, C.E. Krill, Direct observation of grain rotations during coarsening of a semisolid $\mathrm{Al}-\mathrm{Cu}$ alloy, PNAS PLUS. 113 (2016) 5998-6007.

[62] R. Quey, P.R. Dawson, F. Barbe, Large-scale 3D random polycrystals for the finite element method: Generation, meshing and remeshing, Comput. Methods Appl. Mech. Eng. 200 (2011) $1729-1745$.

[63] M. Messner, A. Beaudoin, R. Dodds, Consistent crystal plasticity kinematics and linearization for the implicit finite element method, Eng. Comput. 32 (2015) 1526-1548.

[64] R. Pokharel, R.A. Lebensohn, Instantiation of crystal plasticity simulations for micromechanical modelling with direct input from microstructural data collected at light sources, Scr. Mater. 132 (2017) 73-77.

[65] S.L. Wong, P.R. Dawson, Influence of directional strength-to-stiffness on the elastic - plastic transition of fcc polycrystals under uniaxial tensile loading, Acta Mater. 58 (2010) 1658-1678. 


\section{Tables}

Table 1. Results from the indexing and stress analysis of the diffraction data. The table lists quantities averaged over the entire set of grains (after merging of the five illuminated layers).

\begin{tabular}{|c|c|c|c|c|c|c|c|c|}
\hline \multirow[t]{2}{*}{$\begin{array}{l}\text { Defor- } \\
\text { mation } \\
{[\%]}\end{array}$} & \multirow[t]{2}{*}{$\begin{array}{l}\text { No. } \\
\text { of } \\
\text { grains }\end{array}$} & \multirow[t]{2}{*}{$\begin{array}{l}\text { Spots } \\
\text { per } \\
\text { grain }\end{array}$} & \multirow{2}{*}{$\begin{array}{l}\text { Volume } \\
\text { weighted } \\
\text { tensile } \\
\text { stress } \\
\left(\sigma_{33}\right) \\
{[\mathrm{MPa}]}\end{array}$} & \multirow{2}{*}{$\begin{array}{l}\text { Volume } \\
\text { weighted } \\
\text { tensile } \\
\text { strain } \\
\left(\varepsilon_{33}\right) \\
{\left[10^{-4}\right]}\end{array}$} & $\begin{array}{l}\text { Volume } \\
\text { weighted } \\
\text { error bars }\end{array}$ & \multirow{2}{*}{\multicolumn{3}{|c|}{$\begin{array}{lll}\text { Grain-resolved error bars } \\
& & \\
& & \\
\sigma_{33} & \left(\sigma_{11+} \sigma_{22) / 2}\right. & \left(\sigma_{12+} \sigma_{13+} \sigma_{23}\right) / 3 \\
{[\mathrm{MPa}]} & {[\mathrm{MPa}]} & {[\mathrm{MPa}]}\end{array}$}} \\
\hline & & & & & $\begin{array}{l}\sigma_{33} \\
{[\mathrm{MPa}]}\end{array}$ & & & \\
\hline 0 & 357 & 209 & 10 & -0.02 & 14 & 0.3 & 21 & 8 \\
\hline 0.1 & 357 & 209 & 174 & 9.6 & 14 & 14 & 21 & 8 \\
\hline 1 & 345 & 206 & 205 & 11.7 & 15 & $\begin{array}{ll}0.4 & 15\end{array}$ & 22 & 9 \\
\hline 3 & 315 & 179 & 247 & 14.0 & 59 & $1.4 \quad 59$ & 86 & 33 \\
\hline
\end{tabular}

Table 2. Slip systems in Bishop-Hill notation

Plane $\quad(111) \quad(\overline{1} \overline{1} 1) \quad(\overline{1} 11)$

Direction $\quad[01 \overline{1}][\overline{1} 01][1 \overline{1} 0] \quad[0 \overline{1} \overline{1}][101][\overline{1} 10] \quad[01 \overline{1}][101][\overline{1} \overline{1} 0] \quad[0 \overline{1} \overline{1}][\overline{1} 01][110]$

$\begin{array}{lllllllllllll}\text { Notation } & \text { a1 } & \text { a2 } & \text { a3 } & \text { b1 } & \text { b2 } & \text { b3 } & \text { c1 } & \text { c2 } & \text { c3 } & \text { d1 } & \text { d2 } & \text { d3 }\end{array}$ 
Table 3. Schmid factors in uniaxial tension for the five orientations selected for detailed analysis.

\begin{tabular}{|c|c|c|c|c|c|c|c|c|c|c|c|}
\hline \multirow[t]{2}{*}{ Orientation } & \multicolumn{11}{|c|}{ Slip systems } \\
\hline & a1 & a2 & a3 & b1 & $\overline{b 2}$ & b3 & $\mathrm{c} 1$ & $\mathrm{c} 2$ & $\mathrm{c} 3$ & $\begin{array}{ll}\mathrm{d} 1 & \mathrm{~d} 2\end{array}$ & $\mathrm{~d} 3$ \\
\hline$[100]$ & 0.00 & -0.41 & 0.41 & 0.00 & -0.41 & 0.41 & 0.00 & -0.41 & 0.41 & $0.00-0.41$ & 0.41 \\
\hline$[110]$ & 0.41 & -0.41 & 0.00 & 0.41 & -0.41 & 0.00 & 0.00 & 0.00 & 0.00 & $0.00 \quad 0.00$ & 0.00 \\
\hline$[321]$ & 0.17 & -0.35 & 0.17 & 0.35 & -0.47 & 0.12 & 0.00 & 0.00 & 0.00 & $-0.17-0.12$ & 0.29 \\
\hline 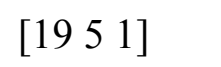 & 0.11 & -0.47 & 0.37 & 0.15 & -0.49 & 0.34 & -0.05 & 0.27 & 0.33 & $-0.09-0.28$ & 0.38 \\
\hline [111] & 0.00 & 0.00 & 0.00 & 0.27 & -0.27 & 0.00 & 0.00 & 0.27 & -0.27 & -0.270 .00 & 0.27 \\
\hline
\end{tabular}

Table 4. Critically stressed slip systems in the five Bishop-Hill stress states expected in the stereographic triangle in Figure 3.

\begin{tabular}{ll}
\hline Stress state & Critically stressed slip systems \\
\hline -BH2 & $-\mathrm{a} 2, \mathrm{a3},-\mathrm{b} 2, \mathrm{~b} 3,-\mathrm{c} 2, \mathrm{c} 3,-\mathrm{d} 2, \mathrm{~d} 3$ \\
\hline BH6 & $\mathrm{a} 1,-\mathrm{a} 2, \mathrm{~b} 1,-\mathrm{b} 2,-\mathrm{c} 1, \mathrm{c} 2,-\mathrm{d} 1, \mathrm{~d} 2$ \\
\hline -BH12 & $-\mathrm{a} 2, \mathrm{a} 3,-\mathrm{b} 2, \mathrm{~b} 3,-\mathrm{c} 1, \mathrm{c} 3,-\mathrm{d} 1, \mathrm{~d} 3$ \\
\hline BH17 & $-\mathrm{a} 2, \mathrm{a} 3, \mathrm{~b} 1,-\mathrm{b} 2,-\mathrm{d} 1, \mathrm{~d} 3$ \\
\hline BH28 & $\mathrm{b} 1,-\mathrm{b} 2, \mathrm{c} 2,-\mathrm{c} 3,-\mathrm{d} 1, \mathrm{~d} 3$ \\
\hline
\end{tabular}


Table 5. Parameters used in the Warp3D simulations.

\begin{tabular}{ll}
\hline $\mathrm{m}$ & 5.0 \\
$\theta_{0}$ & $720 \mathrm{MPa}$ \\
$\tau_{C R S S}$ & $85 \mathrm{MPa}$ \\
$\tau_{v}$ & $130 \mathrm{MPa}$ \\
\hline
\end{tabular}




\section{Figure captions}

Figure 1. a) Experimental stress-strain curve for the uniaxial tensile test of the sample and simulated curve using Warp3D (see section 5.3 for simulation details). b) Schematic of the 3DXRD and tensile setup.

Figure 2. Tensile strain a)-b) and stress c)-d) components along the tensile axes of all individual grains at $0.1 \%$ and $1 \%$ deformation.

Figure 3. Characteristics of the stress state of all individual grains at $0.1 \%$ and $1 \%$ deformation: a)-b) coaxiality, c)-d) triaxiality, and e)-f) Lode angle

Figure 4. Orientation dependence of the five Bishop-Hill stress states and the five orientations selected for detailed analysis.

Figure 5. RSS-values for three selected grains and the average for 22 grains near [100]. The critically stressed slip systems in the expected Bishop-Hill state (-BH2) are marked in red.

Figure 6. RSS-values for three selected grains and the average for 7 grains near [111]. The critically stressed slip systems in the expected Bishop-Hill state (BH28) are marked in blue.

Figure 7. RSS-values for three selected grains and the average for 19 grains near [110]. The critically stressed slip systems in the expected Bishop-Hill state (BH6) are marked in green.

Figure 8. RSS-values for three selected grains and the average for 26 grains near [321]. The three selected grains represent three different Bishop-Hill stress states (BH17, BH28 and BH6), and the critically stressed systems are marked by corresponding colours (grey, blue and green).

Figure 9. RSS-values for three selected grains and the average for 8 grains near [19 5 1]. The critically stressed slip systems in the expected Bishop-Hill state (-BH12) are marked in orange. The red colour 
for grain $\mathrm{N}$ marks the systems of $-\mathrm{BH} 2$ and the dark colour for grain $\mathrm{O}$ indicates that the highly stressed systems do not match any Bishop-Hill state.

Figure 10. Experimentally observed orientation dependence of the Bishop-Hill stress states. The black lines indicate the experimentally determined subdivision of the stereographic triangle. The coloured background illustrate the theoretical orientation dependence. Crosses mark grains not in a BishopHill state at $1 \%$ deformation, whereas coloured circles mark grains identified as being in a BishopHill state.

Figure 11. Predictions from using the finite-element crystal plasticity code Warp3D. Tensile strain a)-b) and stress c)-d) components along the tensile axes of all individual grains at $0.1 \%$ and $1 \%$ deformation for comparison with the experimental data in Figure 2.

Figure 12. Predictions from using the finite-element crystal plasticity code Warp3D. a)-b) coaxiality, c)-d) triaxiality, and e)-f) Lode angle for $0.1 \%$ and $1 \%$ deformation. For comparison with the experimental quantities in Figure 3.

Figure 13. Bishop-Hill states assigned based on the CPFEM simulations for comparison with Figure 10. 


\section{Uniaxial tensile tests}

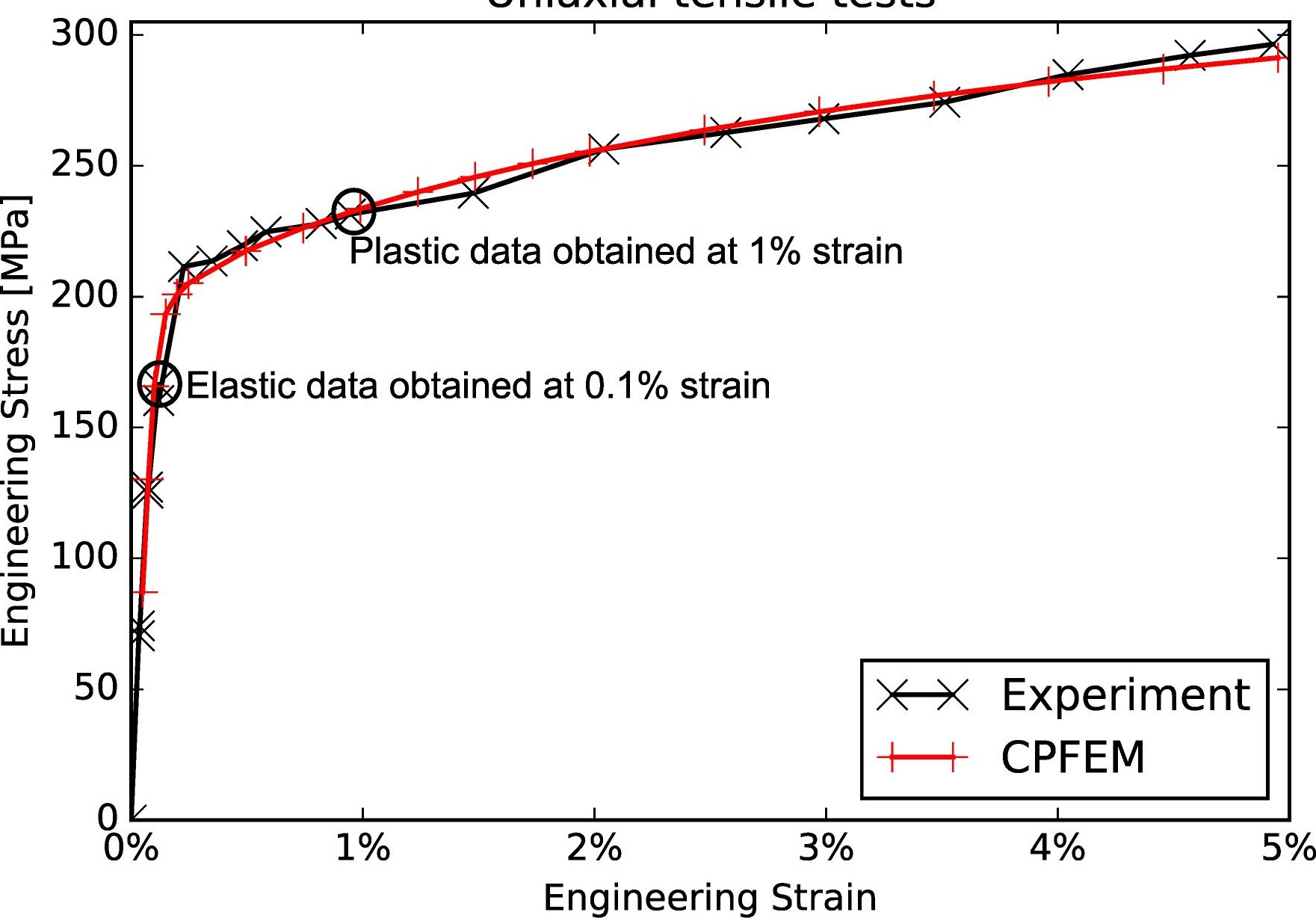


BH28 


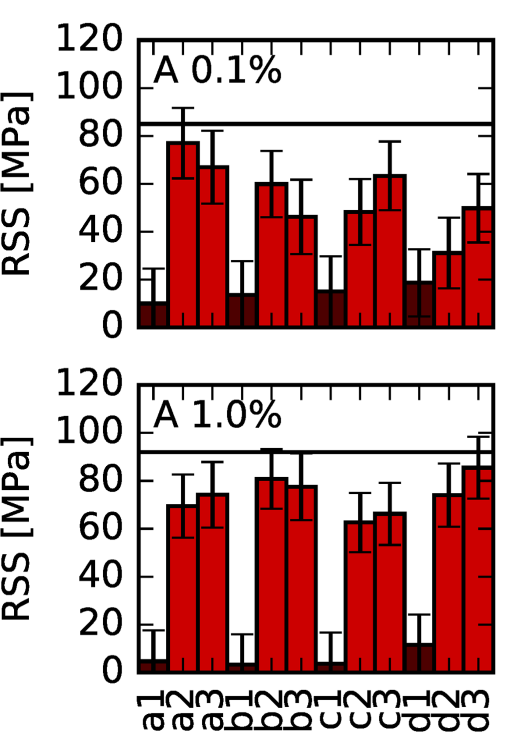

Resolved shear stresses <100>
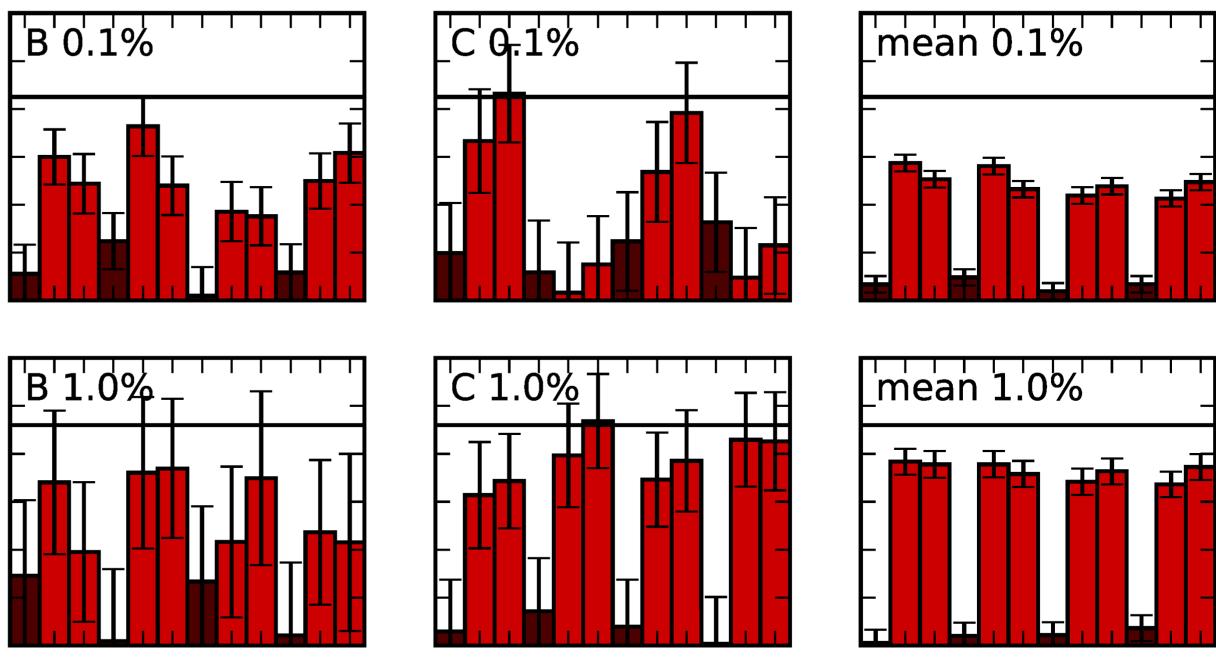

न्रm-

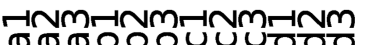

नINm-1Nm-INm-1nm

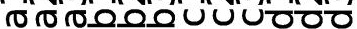



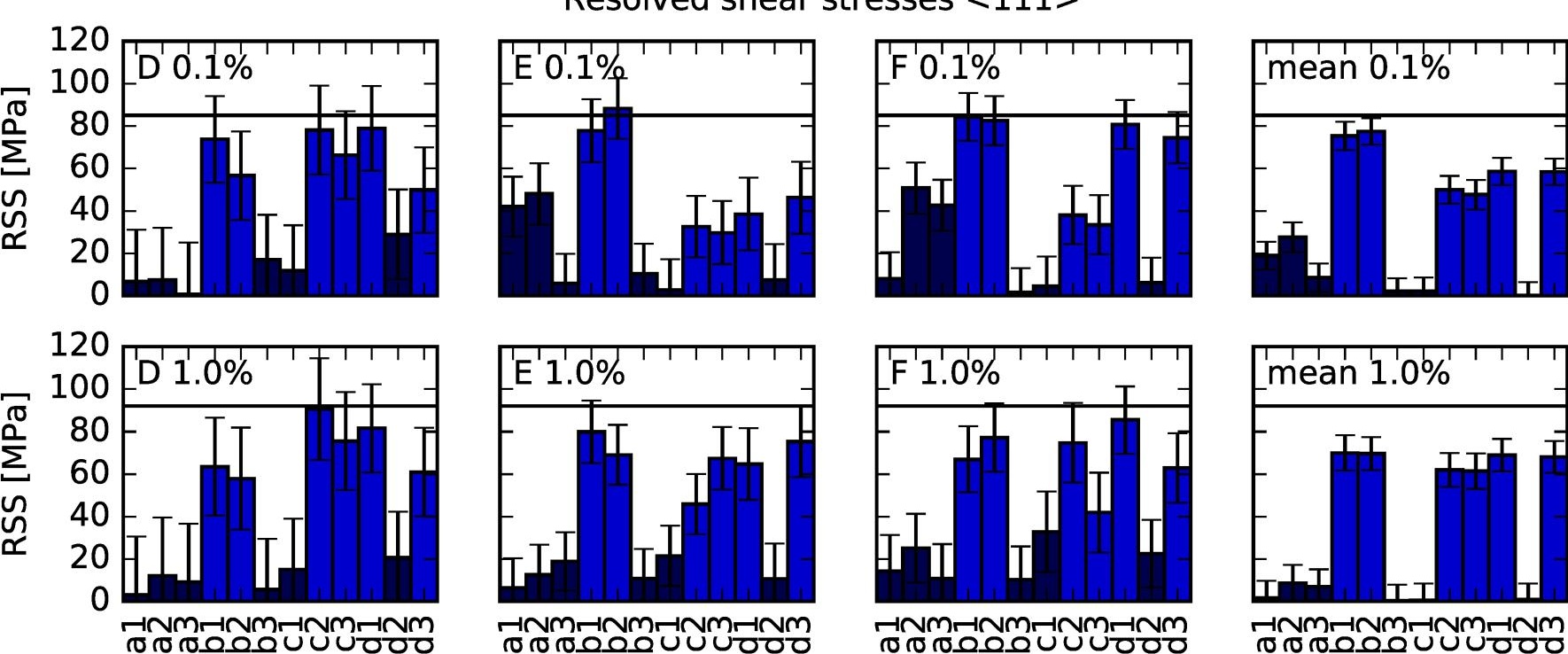

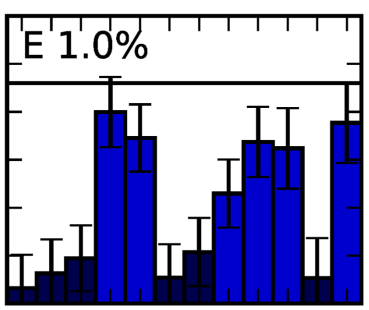

नINm-INm-INm-INm ס

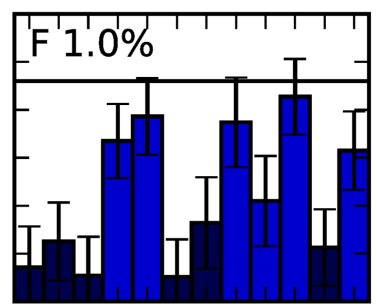

HNm-INm-INm-INm ס

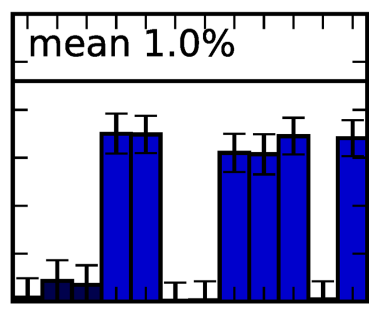

HNm-INm-INm-INm

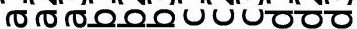




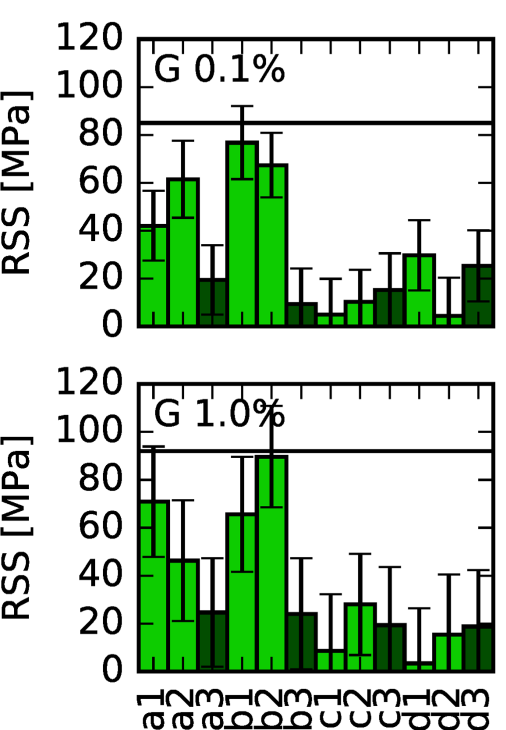

Resolved shear stresses <110>
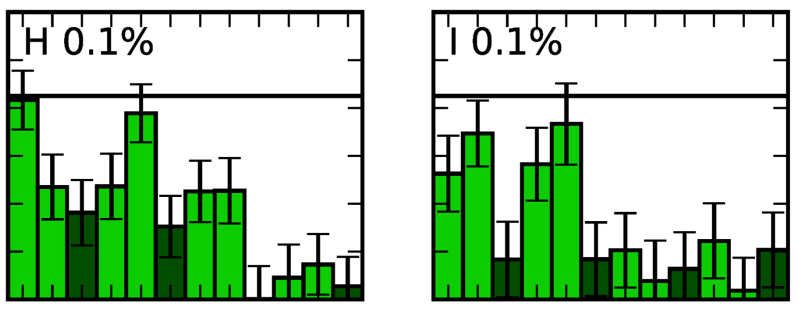

mean $0.1 \%$
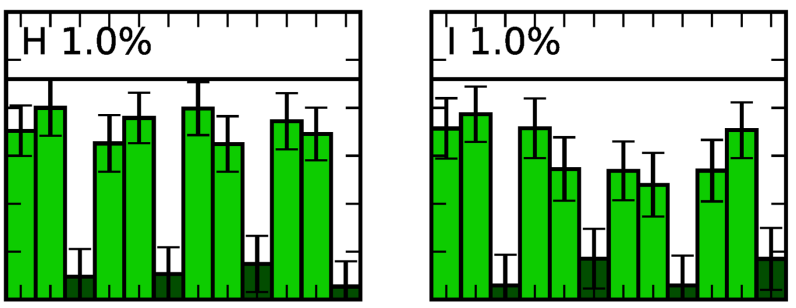

नINm-INm-NM-INm

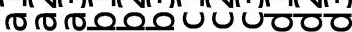

नINM-INM-INM-INm ס ס ס

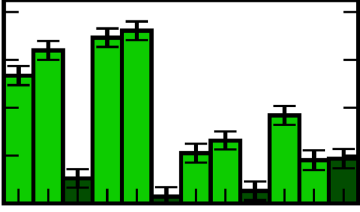

mean $1.0 \%$

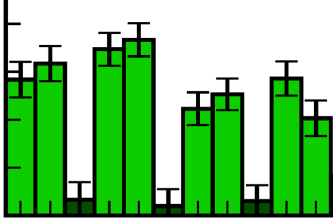

mmm

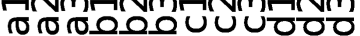



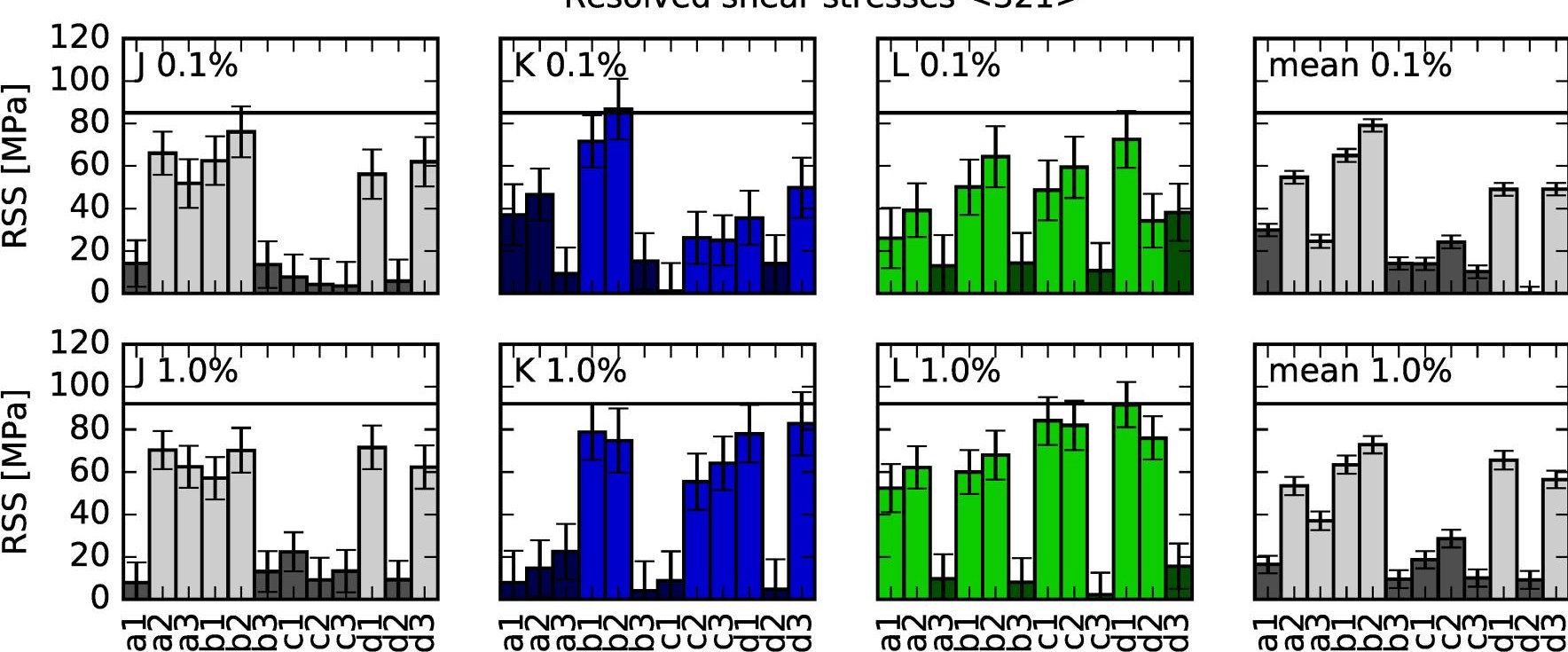


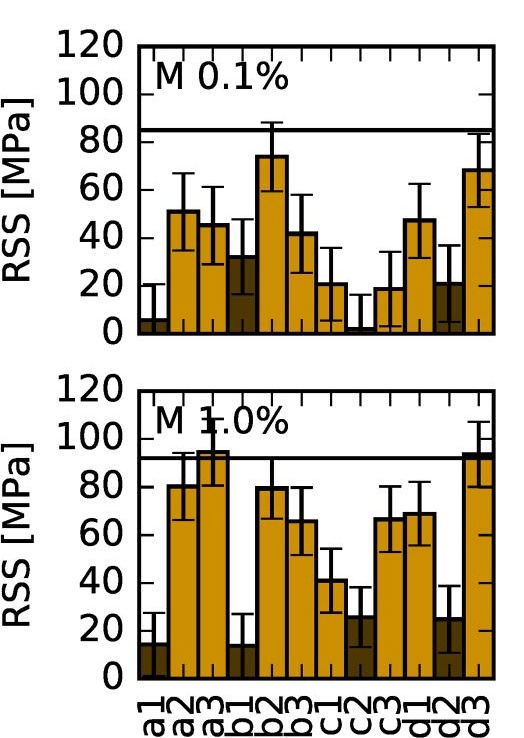

Resolved shear stresses <19 5 1>
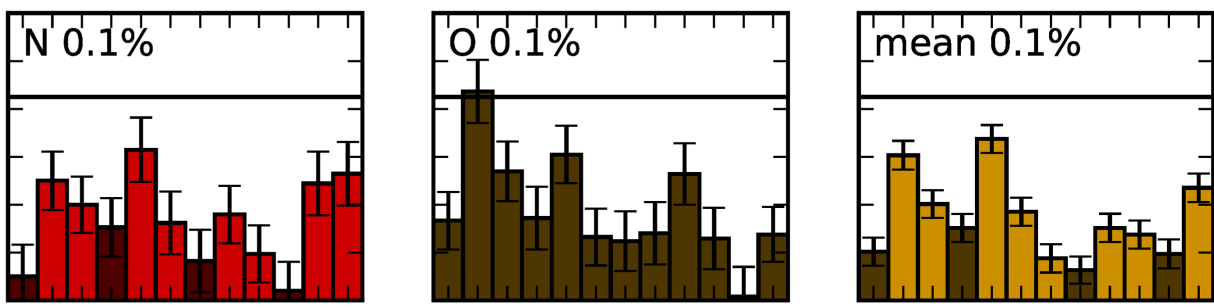

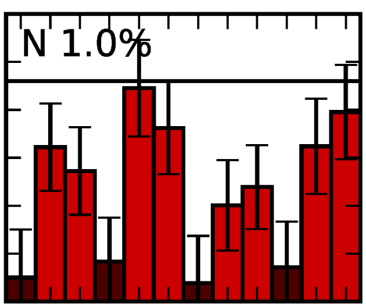

FNm-INm-nMm ס ס

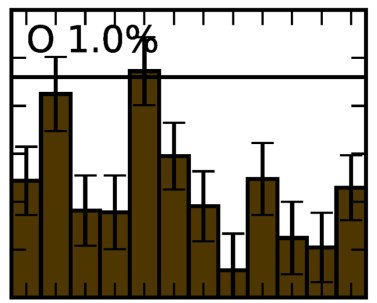

नINm-INm-INm-INm

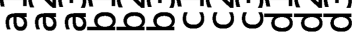

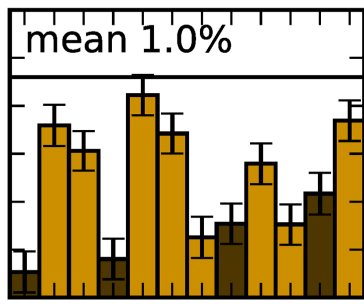

HNM-INm- NMrinm סَర 


\section{Bishop-Hill stress states $<111>$}

$1 \%$ deformation

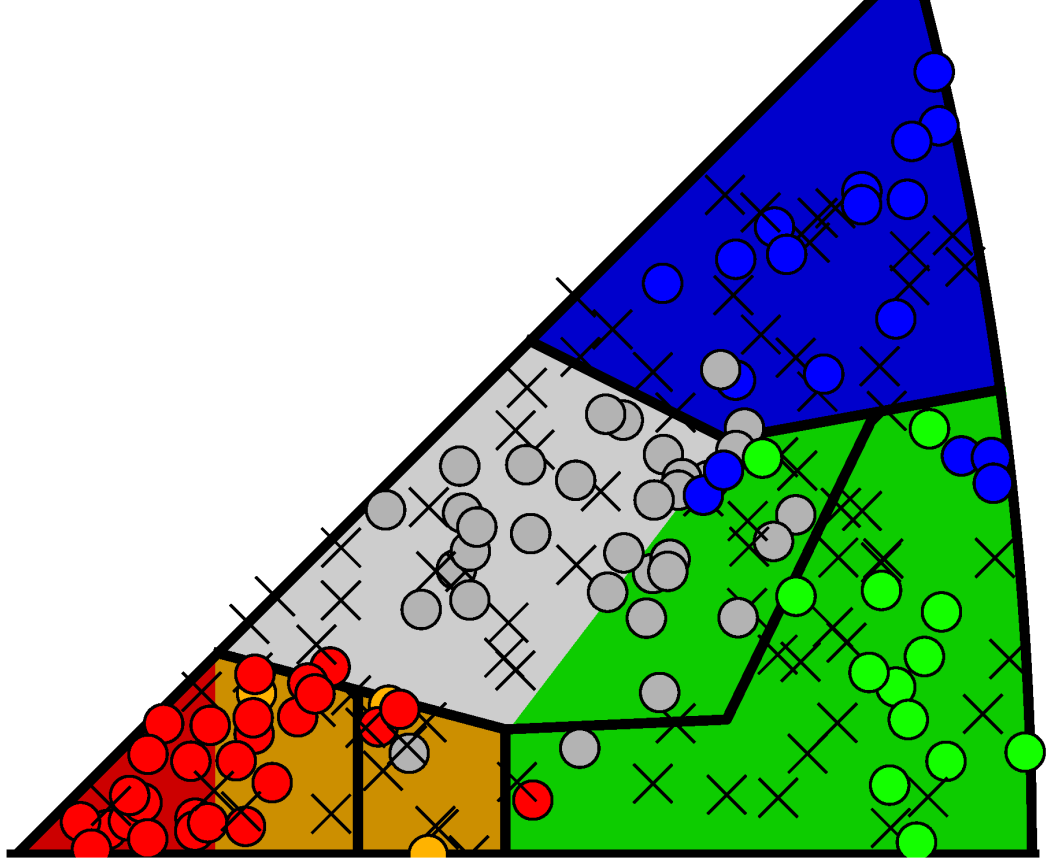

$<100>$

$<110>$ 
a) $\epsilon_{33}$ in sample coordinates $<111>\epsilon_{33}^{s}\left[\cdot 10^{-4}\right]$

b) $\epsilon_{33}$ in sample coordinates $<111>$

$0.1 \%$ deformation CPFEM

08889

8880

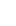

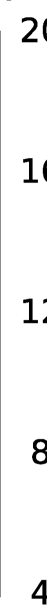

16

12

$1 \%$ deformation

CPFEM

8

$4<100>$

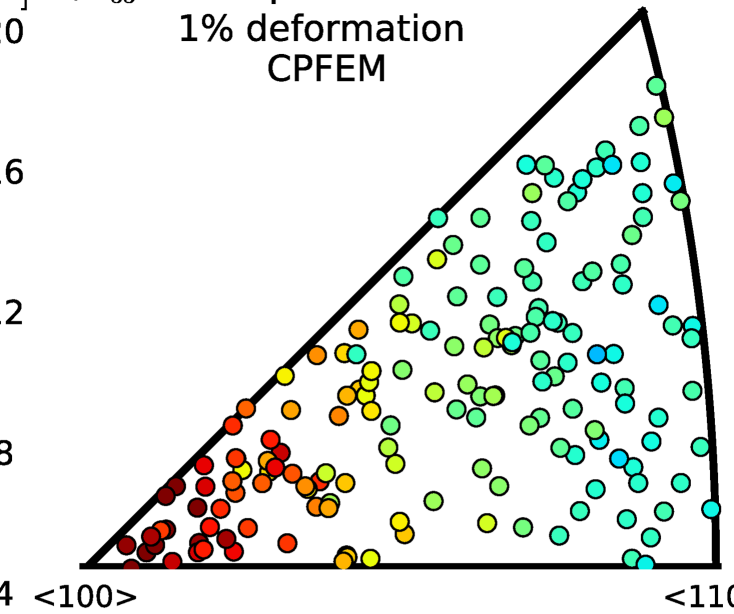

c) $\sigma_{33}$ in sample coordinates <111> $\sigma_{33}^{s}[\mathrm{MPa}]$ d) $\sigma_{33}$ in sample coordinates <111>

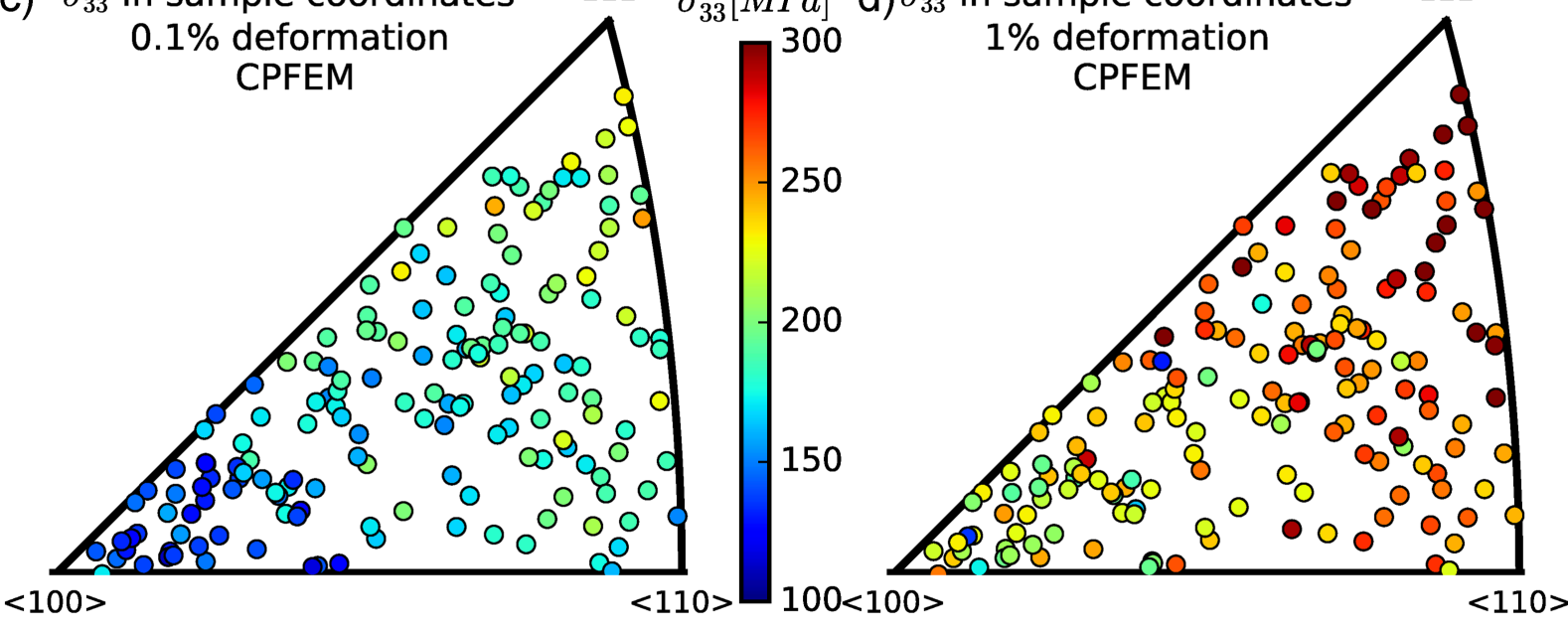

e)

Lode angle

$0.1 \%$ deformation

CPFEM
$1 \%$ deformation

CPFEM $\left\{\begin{array}{l}0.44 \\ 0.35 \\ 0.26 \\ 0.17 \\ 0.09\end{array}\right.$
Lode angle $<111>$

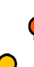

$00_{0}^{0} 00$ 
a)

Coaxiality

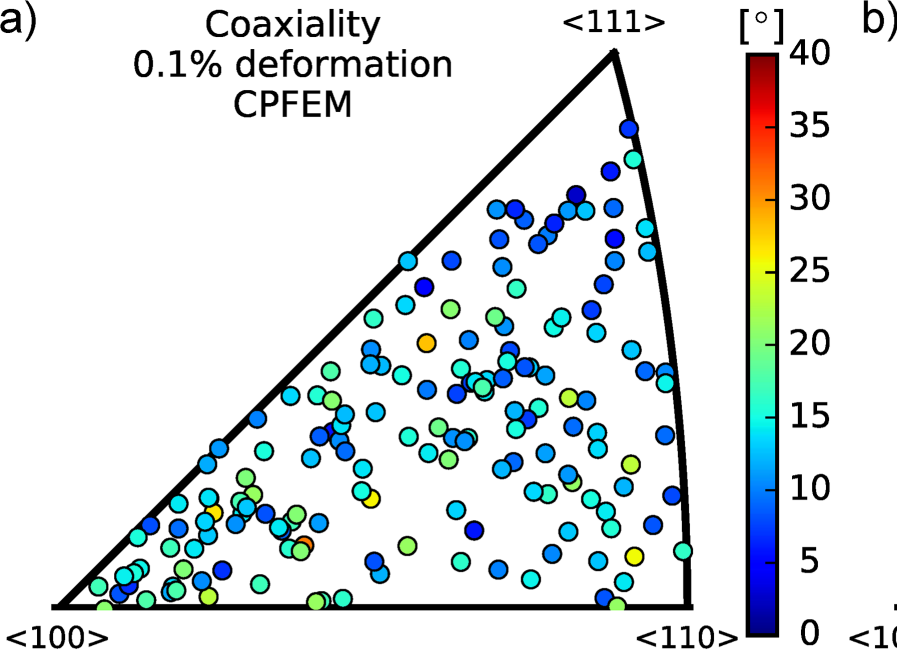

40 b)

35

30

25

20

15

10

5
1\% deformation

CPFEM
C) $<100>$

Triaxiality

$0.1 \%$ deformation CPFEM e)

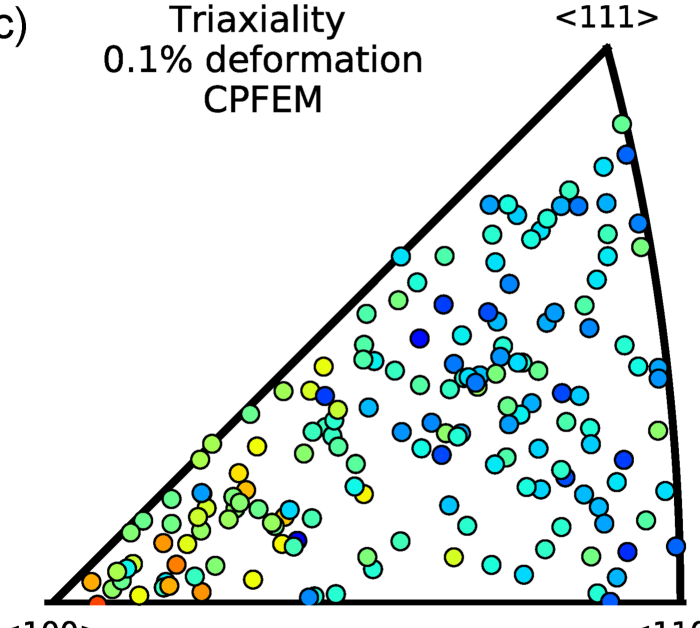

$-0.60$

0.40

0.20

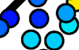

$8 \%$

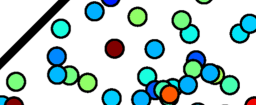
88

$0.80 d)$ O O 80 80 0800

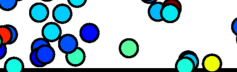
$8^{\circ}$ $000^{\circ}$

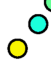
$\circ \circ$

Lode angle

$0.1 \%$ deformation CPFEM
$<111>$ [rad]
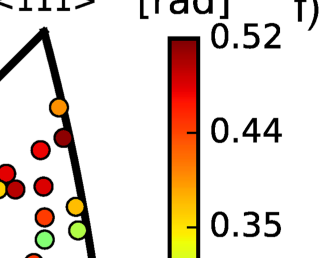

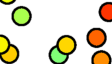
100000 co 0 o o o o 0 .

$\circ 8$.

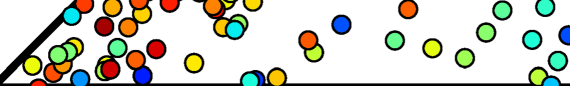
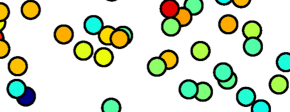

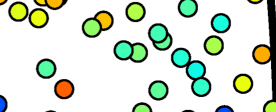

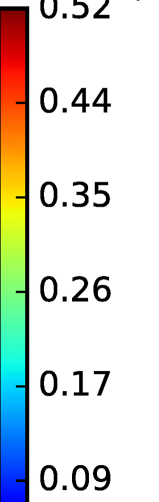
$<110>0.00_{<100>}$
Lode angle

$1 \%$ deformation

CPFEM
Triaxiality 1\% deformation
CPFEM 1\% deforma
CPFEM
$<111>$

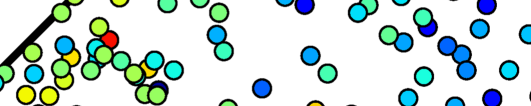

$808^{\circ} 000^{\circ} 80$

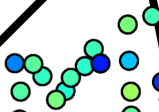

og

808

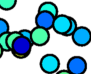

of

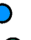

0

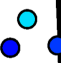


Bishop-Hill stress states $<111>$

$1 \%$ deformation CPFEM

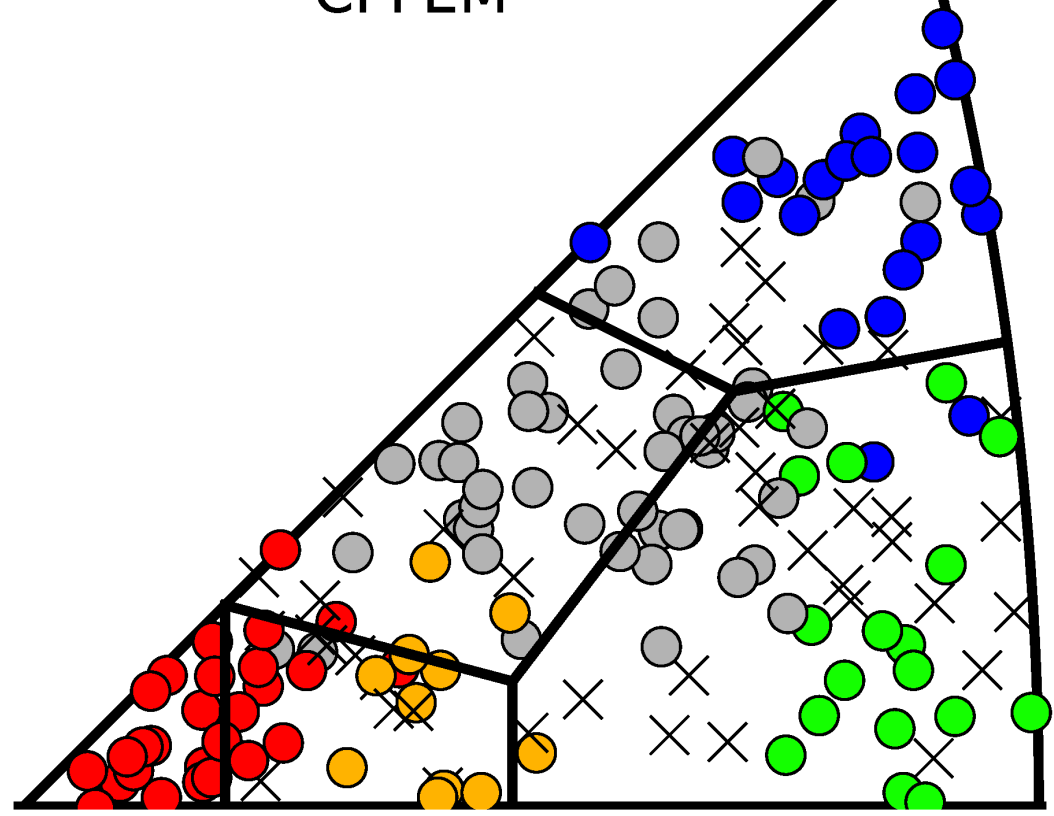

$<100>$

$<110>$ 
Bishop-Hill stress states $<111>$ $1 \%$ tensile elongation

Measured grains on top of theoretical orientation dependence 